\title{
The age-related performance decline in Ironman triathlon starts earlier in swimming than in cycling and running
}

\author{
Käch, Ilja W ; Rüst, Christoph A ; Nikolaidis, Pantelis T ; Rosemann, Thomas ; Knechtle, Beat
}

\begin{abstract}
In Ironman triathlon, the number of overall male and female finishers increased in the last 30 years, while an improvement in performance has been reported. Studies concluding these numbers only analysed the top ten athletes per age group instead of all finishers, therefore a selection bias might have occurred. The aim of the present study was to investigate participation, performance and the age-related performance decline of all pro and age group triathletes ranked in all Ironman triathlons held worldwide between 2002 and 2015. Split and overall race times of 329,066 (80\%) male and 81,815 (20\%) female athletes competing in 253 different Ironman triathlon races were analysed. The number of finishers increased in all age groups with exception of women in age group 75-79 years. In pro athletes, performance improved in all disciplines. In age group athletes, performance improved in younger age groups for running (18-24 to 40-44 years) and older age groups for swimming (50-54 to 65-69 years) and cycling (35-39 to 55-59 years), while it impaired in younger age groups for swimming (18-24 to $45-49$ years) and cycling (18-24 to 30-34), and older age groups in running (45-49 to 70-74 years). The agerelated performance decline started in women in age group 25-29 years in swimming and in age group 30-34 years in cycling, running and overall race time, whereas it started in men in age group 25-29 years in swimming and in age group 35-39 years in cycling, running and overall race time. For athletes and coaches, performance improved in younger age groups for running and older age groups for swimming and cycling and the age-related decline in performance started earlier in swimming than in cycling and running. In summary, women should start competing in Ironman triathlon before the age of 30 years and men before the age of 35 years to achieve their personal best Ironman race time.
\end{abstract}

DOI: https://doi.org/10.1519/JSC.0000000000001796

Posted at the Zurich Open Repository and Archive, University of Zurich

ZORA URL: https://doi.org/10.5167/uzh-136612

Journal Article

Accepted Version

Originally published at:

Käch, Ilja W; Rüst, Christoph A; Nikolaidis, Pantelis T; Rosemann, Thomas; Knechtle, Beat (2018). The age-related performance decline in Ironman triathlon starts earlier in swimming than in cycling and running. Journal of Strength and Conditioning Research, 32(2):379-395.

DOI: https://doi.org/10.1519/JSC.0000000000001796 


\title{
The age-related performance decline in Ironman triathlon starts earlier in swimming than in cycling and running
}

\author{
Ilja Käch ${ }^{1}$, Christoph A. Rüst ${ }^{1}$, Pantelis T. Nikolaidis ${ }^{3}$, \\ Thomas Rosemann ${ }^{1}$, Beat Knechtle ${ }^{1,2}$
}
1 Institute of Primary Care, University of Zurich, Zurich, Switzerland Gesundheitszentrum St. Gallen, St. Gallen, Switzerland Exercise Physiology Laboratory, Nikaia, Greece

\author{
Corresponding author \\ Prof. Dr.med. Beat Knechtle \\ Facharzt FMH für Allgemeinmedizin \\ Gesundheitszentrum St. Gallen \\ Vadianstrasse 26 \\ 9001 St. Gallen \\ Switzerland \\ Telefon \\ +41(0) 712269300 \\ Telefax \\ +41(0) 712269301 \\ e-mail \\ beat.knechtle@hispeed.ch
}

\section{Abstract}

In Ironman triathlon, the number of overall male and female finishers increased in the last 30 years, while an improvement in performance has been reported. Studies concluding these numbers only analysed the top ten athletes per age group instead of all finishers, therefore a selection bias might have occurred. The aim of the present study was to investigate participation, performance and the age-related performance decline of all pro and age group triathletes ranked in all Ironman triathlons held worldwide between 2002 and 2015. Split and overall race times of 329,066 (80\%) male and 81,815 (20\%) female athletes competing in 253 different Ironman triathlon races were analysed. The number of finishers increased in all age groups with exception of women in age group 75-79 years. In pro athletes, performance improved in all disciplines. In age group athletes, performance improved in younger age groups for running (18-24 to 40-44 years) and older age groups for swimming (50-54 to 65-69 years) and cycling (35-39 to 55-59 years), while it impaired in younger age groups for 
swimming (18-24 to 45-49 years) and cycling (18-24 to 30-34), and older age groups in running (45-49 to 70-74 years). The age-related performance decline started in women in age group 25-29 years in swimming and in age group 30-34 years in cycling, running and overall race time, whereas it started in men in age group 25-29 years in swimming and in age group 35-39 years in cycling, running and overall race time. For athletes and coaches, performance improved in younger age groups for running and older age groups for swimming and cycling and the age-related decline in performance started earlier in swimming than in cycling and running. In summary, women should start competing in Ironman triathlon before the age of 30 years and men before the age of 35 years to achieve their personal best Ironman race time.

Key words: Age group, sex difference, master athlete, worldwide trend

\section{INTRODUCTION}

Ironman triathlon is considered as one of the most challenging ultra-endurance events in the world (31). The classical Ironman triathlon consists of three disciplines - swimming, cycling and running (performed in this order) - and is held over the distance of $3.8 \mathrm{~km}$ swimming, $180 \mathrm{~km}$ cycling and $42.2 \mathrm{~km}$ running (4). Triathlon presents an intriguing model to analyse the age-related trends in endurance performance, since the trends can be analysed in the same subject for overall performance and for the three disciplines separately $(5,27,29,33)$.

For athletes and coaches the age of peak Ironman performance is important in planning a career (27). The age of peak Ironman performance has been reported at $~ 32-34$ years for both women and men $(27,47,55)$. However, differences seem to exist in the age of peak Ironman performance between qualifiers for 'Ironman Hawaii' and 'Ironman Hawaii' itself. Over the last three decades, the age of the annual top ten finishers in 'Ironman Hawaii' increased in 
male and female athletes (10). In contrast, in 'Ironman Switzerland', a qualifier race for 'Ironman Hawaii', the age of peak Ironman performance increased for the annual top ten women between 1995 and 2011, but not for men (45). Indeed, a study showed a lower proportion of finishes and slower race times for certain age groups competing in 'Ironman Hawaii' compared to its qualifier races, as well as a higher percentage of female and lower percentage of male finishers (56). Therefore, the different participation rate of certain age group athletes in 'Ironman Hawaii' compared to its qualifier races might lead to a selection bias.

Over the last decades, the participation of age group athletes increased both in "Ironman Hawaii' (32) and in qualifier races such as 'Ironman Switzerland' (54). In 'Ironman Switzerland', the number of overall male finishers increased in the last years, while the relative participation of master athletes considerably increased (54). Also in 'Ironman Hawaii', the number of overall male and female finishers increased in the last 30 years, while the relative participation of master athletes increased (32). In addition to the increase in participation, an improvement in performance of elite athletes has been reported $(10,45)$. Similarly to elite athletes, master athletes improved their Ironman triathlon performance over the last decades, both in 'Ironman Hawaii' (32) and 'Ironman Switzerland' (54). However, analysing only the top ten athletes competing in 'Ironman Hawaii' may lead to a severe selection bias since the majority of Ironman athletes are recreational age group athletes and less than one percent of the overall number of those participating in any Ironman triathlon is considered.

Up to now, the performance and participation trends in male and female Ironman triathletes have been analysed only for single races such as an Ironman qualifier (e.g. 'Ironman Switzerland') $(45,54)$ and 'Ironman Hawaii' (32). The trend of an increase in participation and an improvement in performance of age group athletes has been reported only for single 
Ironman races; thus, the assumption that it reflects a worldwide trend needs verification.

Considering other ultra-endurance performances, a recent study reported that ultramarathoners competing in time-limited races of different durations became slower while getting older in the last 40 years (23), which is contradictory to the findings for Ironman athletes competing in 'Ironman Hawaii', where the annual ten fastest became faster and older in the last 30 years (10). According to Knechtle et al. (23), the most probable explanation for the discrepancy between these two findings is the different sampling methods. Although Gallmann et al. (10) analysed the annual ten fastest men and women in 'Ironman Hawaii', Knechtle et al. (23) included all annual finishers in their analysis of ultra-marathoners of different race durations. An analysis including all recorded finishers of all races instead of a fixed number of athletes, for example the top ten per age group during a certain period (48) might eliminate a potential selection bias.

Therefore, the aim of the present study was to investigate participation and performance trends of pro and all age group athletes ranked in all Ironman triathlon races held worldwide between 2002 and 2015 in order to analyse the worldwide trend. We hypothesized that the participation of age group athletes would increase while their performance would improve. In comparison to previous studies we investigated all finishers in all Ironman races held worldwide for the studied period, therefore minimizing the selection bias caused by selecting only single races and/or considering only a fixed number of finishers instead of all finishers. Furthermore, we analysed the age-related performance decline for swimming, cycling, running and overall race time. 


\section{METHODS}

\section{Experimental Approach to the Problem}

To test our hypotheses, all women and men who finished an Ironman triathlon between 2002 and 2015 were considered. All data were obtained from the official website of Ironman triathlon races (http://eu.ironman.com/events/triathlon-races).

\section{Subjects}

Split and overall race times of successful female and male pro and age group finishers of all Ironman races held worldwide and documented by the official Ironman triathlon website between 2002 and 2015 were collected, since full data were only available starting in the year 2002. Before 2002, athletes were not ranked in age groups. Due to missing data or missing age group assignment the data of twelve races could not be gathered. All procedures used in the study were approved by the Institutional Review Board of Kanton St. Gallen, Switzerland with a waiver of the requirement for informed consent of the participants given the fact that the study involved the analysis of publicly available data.

\section{Procedures}

Split and overall race times of a total of 343,079 male and 85,923 female finishers competing in 253 Ironman races were collected (Table 1). From this set of data a total of 14,013 male (4.7\%) and 4,108 female (5.5\%) athletes had to be excluded either due to shortened course lengths in five races or due to missing or incorrect split times. Ultimately, a total of 329,066 (80 \%) male and 81,815 (20\%) female athletes were considered for final data analysis. To analyse performance and participation trends male and female athletes were categorised into pro and age groups of 5-year intervals (i.e. from 18-24 to 75-79 years). Table 2 shows the number of finishers per calendar year and per age group. 


\section{Statistical Analyses}

The change in participation across years was investigated using single linear regression analyses. To investigate changes in performance of finishers, a mixed-effects regression model with finisher as random variable to consider finishers who completed several races was used. We included sex and calendar year as fixed variables. Models were calculated for each age group and the final model was selected by means of Akaike information Criterion (AIC). Sex difference was calculated using the equation ([time in men] - [time in women] / [time in men] $\times 100$ ). In order to facilitate reading all sex differences were transformed to absolute values before analysing and afterwards investigated for changes by linear regression models. The change in sex difference across years was investigated using single linear regression analyses. Performance in split and overall race times for all athletes ranked in all age groups from 2002 to 2015 were compared using one-way analysis of variance (ANOVA) with subsequent Tukey's multiple comparison tests with a single pooled variance. A two-way ANOVA examined the sexxage group interaction and the main effects of sex and age group on race time of each discipline and overall performance. Within each sex, a one-way ANOVA examined differences among age groups, too. Statistical analyses were performed using IBM SPSS Statistics (Version 22, IBM SPSS, Chicago, IL, USA) and GraphPad Prism (Version 6.01, GraphPad Software, La Jolla, CA, USA). Significance was accepted at $\mathrm{p}<0.05$ (twosided for $t$-tests). Data are given as mean \pm standard deviation (SD). 


\section{RESULTS}

\section{Participation trends}

From 2002 to 2015 , a total of 81,815 female athletes completed at least in one of the 253 included Ironman races (Table 1). The number of finishers increased significantly between 2002 and 2015 in all female age groups from 18-24 to 65-69 ( $<<0.0001)$ years as well as in the age group 70-74 years $(r=0.42, p=0.013)$ except age group 75-79 years $(r=0.02, p=0.60)$ (Table 2). During the same period, a total of 329,066 male athletes completed at least in one of the 253 included Ironman races (Table 1). The number of finishers increased significantly in all age groups from 18-24 to 75-59 years $(\mathrm{p}<0.0001)$ (Table 2).

\section{Performance trends across calendar years}

In swimming (Tables 3 and 4), pro athletes and athletes in age groups 50-54 to 65-69 years improved their performance (Table 5). Athletes in age groups 18-24 to 45-49 years impaired their performance. In athletes in age groups 70-74 and 75-79 years, performance remained unchanged. Men were faster than women in pro athletes and age group athletes 18-24 to 7074 years, but not 75-79 years. In cycling (Tables 3 and 4), pro athletes and athletes in age groups 35-39 to 55-59 years improved performance, athletes in age groups 18-24 to 30-34 years impaired performance and athletes in age groups 60-64 to 75-79 years showed no changes in performance (Table 6). Men were faster than women in pro athletes and athletes in age group 18-24 to 70-74 years, but not 75-79 years. In running (Tables 3 and 4), pro athletes and age group athletes in age groups 18-24 to 40-44 years improved performance, athletes in age groups 45-49 to 70-74 years impaired performance and in athletes in age group 75-79 years, no changes in performance were detected (Table 7). Men were faster than women in pro athletes and athletes in age groups 18-24 to 65-69 years, but not 70-74 and 75-79 years. 
For overall race time (Tables 3 and 4), pro athletes and athletes in age groups 30-34 and 35-39 years improved performance. Athletes in age groups $18-24,25-29$, and $40-44$ to $65-69$ years impaired performance. In athletes in age groups 70-74 and 75-79 years, no changes in performance were found (Table 8). Men were faster than women in pro athletes and all age group athletes-

\section{Performance by sex and age group}

A two-way ANOVA showed a sexxage group interaction on overall performance and the three split disciplines $\left(\mathrm{p}<0.001, \eta^{2}<0.001\right)$, which was of trivial magnitude. A main effect of sex on overall performance and the three split disciplines, where men were faster than women, was observed $\left(p<0.001, \eta^{2} \leq 0.001\right)$, which was also of trivial magnitude. Age groups differed $(p<0.001)$ for swimming time $\left(\eta^{2}=0.080\right.$, medium ES $)$, cycling time $\left(\eta^{2}=0.069\right.$ medium ES), running time $\left(\eta^{2}=0.068\right.$, medium ES $)$ and overall race time $\left(\eta^{2}=0.091\right.$, medium ES). Pro group was the fastest in all race times (Figure 1). Among the age groups, the 18-24 years age group was the fastest in swimming, the 30-34 years age group in cycling (but it did not differ from 25-29), the 25-29 years age group in running and in overall performance (but it did not differ from 30-34) (Figure 1). Thus, the age-related decline in performance started in the 25-29 years age group in swimming and the 35-39 years age group in cycling, running and overall.

Within each sex, a one-way ANOVA showed that fastest was the pro group in all race times $(p<0.001)$. In women, age groups differed for swimming $\left(p<0.001, \eta^{2}=0.139\right.$, medium ES $)$, cycling $\left(p<0.001, \eta^{2}=0.126\right.$, medium ES $)$, running $\left(p<0.001, \eta^{2}=0.133\right.$, medium ES $)$ and overall race time $\left(\mathrm{p}<0.001, \eta^{2}=0.171\right.$, large ES $)$; the fastest was in age group 18-24 group in swimming and 25-29 group in the other performances (Figure 1). Overall, the age-related decline in performance in women started in age group 25-29 years in swimming and in age group 30-34 years in other performances. In men, age groups differed for swimming 
$\left(p<0.001, \eta^{2}=0.095\right)$, cycling $\left(p<0.001, \eta^{2}=0.082\right)$, running $\left(p<0.001, \eta^{2}=0.081\right)$ and overall race time $\left(\mathrm{p}<0.001, \eta^{2}=0.108\right)$, too; the fastest was age group $18-24$ years in swimming and age group 30-34 years in the other performances (Figure 1). Thus, the age-related decline in performance in men started in age group 25-29 years in swimming, age group 35-39 years in cycling, running and overall.

\section{Sex difference across calendar years}

Between 2002 and 2015 the sex difference decreased in swimming in age groups 25-29 years $\left(r^{2}=0.69, p<0.0001\right), 50-54$ years $\left(r^{2}=0.38, p=0.019\right)$ and 55-59 years $\left(r^{2}=0.66, p=0.0004\right)$ but remained unchanged for all other age groups (Table 9). In cycling, the sex difference in performance decreased in age groups $25-29$ years $\left(r^{2}=0.52, p=0.0037\right), 45-49$ years $\left(r^{2}=0.42\right.$, $\mathrm{p}=0.011)$ and $65-69$ years $\left(\mathrm{r}^{2}=0.47, \mathrm{p}=0.0058\right)$ but remained unchanged for all other age groups (Table 9). In running, the sex difference decreased in pro athletes $\left(r^{2}=0.82, p<0.0001\right)$, increased in athletes in age groups $40-44$ years $\left(r^{2}=0.37, p=0.021\right)$ and $45-49$ years $\left(r^{2}=0.37\right.$, $\mathrm{p}=0.021)$, decreased in athletes in age group 65-69 years $\left(\mathrm{r}^{2}=0.36, \mathrm{p}=0.030\right)$ and remained unchanged in all other age groups (Table 9). For overall race time, the sex difference in performance decreased in age groups 25-29 years $\left(\mathrm{r}^{2}=0.33, \mathrm{p}=0.032\right)$ and $65-69$ years $\left(r^{2}=0.63, p=0.0012\right)$ and remained unchanged in all other age groups (Table 9). 


\section{DISCUSSION}

In the present study, we examined the worldwide participation and performance trends of age group athletes and the age-related performance decline for split and overall race times. The main findings were that $(i)$ participation increased in pro athletes and all age groups, except for women in age group 75-79 years, (ii) performance improved in younger age groups for running and older age groups for swimming and cycling, (iii) the age-related decline in performance started at 25-29 years in swimming for women and men and in cycling, running and overall race time at 30-34 years and 35-39 years for women and men, respectively, and (iv) the sex difference remained stable across years with minor exceptions, where women were able to reduce the sex difference.

\section{Increase in participation in age groups across calendar years}

A first important finding was that the participation in Ironman triathlon over the studied period increased in pro athletes and all age group athletes, except for women in age group 7579 years. This finding is in accordance with previous studies in triathletes and runners. In the last few years, numerous studies investigated the participation trends for different ultraendurance events $(13,18,32,46,47,54)$. In ultra-running, an increased participation has been shown in the 'Western States 100-Mile Endurance Run' held in California, USA (15). With regards to 'Ironman Hawaii' (32) and 'Ironman Switzerland' (54), the participation of age group athletes increased over the last decades, whereas the percentage of master athletes (i.e. athletes older than 35 years) considerably increased. Over the last decades, an increased participation has also been reported in Double $(18)$, Triple $(18,46)$ and Deca Iron ultratriathlon (18). 
Different reasons for the increased participation in ultra-endurance events, especially in Ironman triathlon, have been discussed. Mainly, the increased popularity of Ironman triathlons attracted more athletes and especially more master athletes in recent years $(32,54)$. The increase in participation in master athletes has previously been described and is most likely due to the increased life expectancy (www.oecdbetterlifeindex.org/topics/health/) and increased training facilities for master athletes (32). Another reason might be that the myth of 'Ironman Hawaii' is undiminished and still attracts many ultra-endurance athletes each year. Additionally, the 'Ironman Hawaii' has a substantial advertising appeal, and might therefore also have an impact on the increase in participation in Ironman races in general.

\section{Younger athletes improved in running and older athletes in swimming and cycling}

Another important finding was that performance improved in pro athletes for all disciplines.

Furthermore, performance improved in younger age group athletes for running and older age group athletes for swimming and cycling. Our results are in accordance with previous studies reporting the improved performance of older age group athletes in swimming, cycling and overall race time, as well as the performance improvement in pro athletes.

In the past few years numerous studies investigated performance trends for different ultraendurance events $(10,15,18,22,45,46)$. In the '100 km Lauf Biel' held in Switzerland (22) performance remained stable across years. In the 'Western States 100-Mile Endurance Run' held in California, USA, female runners improved their finishing times across years, while the performance of male runners remained stable (15). In Triple Iron ultra-triathlons male finishers improved their performance across years, whereas female finishers became slower over the years (46). In Double and Deca Iron ultra-triathlons performance remained unchanged over the last decades (18). Regarding Ironman triathlon, recent studies showed an improvement of performance over the last decades $(10,45)$. 
The first official Ironman race was held in 1978 in Hawaii (www.ironman.com). After an initial increase in participation in 'new' sporting events, the age of the participating athletes increases across years leading to an increased participation in older age groups (48). With increasing participation of older athletes, the level of competition rises in older age groups and leads to improvements in athletic performance (2). Athletes who finished an Ironman in its early days (i.e. in the nineties of the last century) at the age of $\sim 25-35$ years would nowadays (i.e. 2016) be at an age of $\sim 50-60$ years. It is very likely that athletes, who have continued their training and competed in Ironman races across years, should be able to preserve their level of performance. The improvement of athletic performance has been progressively greater in older age groups in the past few years (2). Akkari et al. (2) showed that athletic performance in athletes older than 45 years continues to improve compared to younger athletes. They hypothesized that with increasing participation of older athletes the level of competition would raise, leading to an improvement of performance, while the performance of younger athletes would remain stable. Stiefel et al. (53) also showed that master Ironman triathletes have not yet reached their limits. It is also known that master runners suffer more injuries than younger athletes, which limits their performance (36). This might also attribute to the selection process, meaning that successful athletes older than $\sim 40$ years might be less susceptible to injuries through better estimation of the extent of their performance due to their accumulated experience. Also, older athletes might stop competing after an injury, which furthers the selection process in a way that could be best described as 'the survival of the fittest'. As shown in several studies, Ironman triathlon performance has stagnated in younger age groups, while master athletes were still able to improve their performance $(45,54)$. 
Our results also show an improved running performance in younger age group athletes.

Previous studies showed a stagnation in performance trends in younger age group athletes.

This finding could be explained by the different sampling method, which includes all finishers instead of only the top ten finishers. Younger athletes might have improved their running split times as a result of a higher training volume for running in order to close the gap to the top athletes. The unchanged performance in the oldest age group athletes is most likely because of the small sample size due to the low participation in these age groups. Therefore no significant change in performance could be found.

\section{Performance decline starts earlier in swimming than in cycling and running}

A very astonishing finding was that the age-related decline in swimming performance already started in age group 25-29 for both women and men. The performance decline in cycling, running and overall race time started in age group 30-34 years in women and 35-39 years in men.

The earlier decline in performance in women than in men might be associated with the different ages of peak endurance between sexes; this age is 17-21 years in males and 12-15 years in females $(40,44)$. In addition, women show a faster rate of performance decline $(61)$. The earlier decline in swimming performances compared to previous studies can be explained by the different sampling method, which takes all finishers into consideration instead of only the top ten athletes. Therefore the selection bias of previous studies could be eliminated.

To date, the age-related performance decline in endurance $(5,34,35,42,58)$ and ultraendurance performance $(15,22,32)$ has been well documented. Several studies concluded that endurance performance appears to be maintained until the age of $\sim 35-40$ years, with a moderate decline until the age of 50 years and a growing decrease afterwards $(43,57,58)$. After the age of 70 years the greatest decline in endurance performance occurs (30). The decline in endurance performance appears to be caused primarily by an age-related decrease 
in maximum oxygen uptake $\left(\mathrm{VO}_{2} \mathrm{max}\right)$ and lactate threshold $(43,58)$. This decline can be decelerated by non-biological factors such as experience $(25,26)$, learning $(50)$ and mental strength and motivation (41). Said decline can also be regulated by changing both the intensity and the volume of training (58).

Previous studies found that Ironman triathlon performance started to decrease at the age of $\sim 45$ years in swimming and running, and at the age of $\sim 50$ years in cycling (33). With advancing age, athletes move towards longer distances, such as Ironman triathlon (27), where performance is more related to endurance capacities and experience than $\mathrm{VO}_{2}$ max and lactate threshold $(27,32)$. Fitness benefits and social factors appear to be the main drivers for older athletes to perform in Ironman triathlons (51). Therefore, it can be explained that athletes are able to maintain the same level of performance until the age of $\sim 50$ years. Indeed, Leyk et al. $(34,35)$ showed that mean marathon and half-marathon times were virtually identical from the age of $\sim 20$ to $\sim 49$ years and age-related losses did not occur before the age of 50 years. Also, Hoffmann and Wegelin (15) showed that the performance of athletes competing at the age of $\sim 40$ to $\sim 49$ years in a 161-km ultra-marathon was not different from athletes competing in the younger age groups.

The main difference of our study compared to other studies investigating the subject of an age-related decline in endurance performance is the analysis of the selected samples. Instead of only analysing the top athletes of every age group, we analysed all finishers of all age group, therefore eliminating the selection bias. By taking all finishers in an age group into consideration, our results show the average split and overall race times of each age group instead of only the top athletes per age group. Our results showed that the age-related decline in Ironman triathlon performance starts at the age of 25-29 years in swimming and 35-39 years in cycling, running and overall race time. This finding could be explained by the fact that many recreational athletes without former experience possibly participate in Ironman 
triathlons leading to a broad spectrum of split and overall race times. The average race times in age groups are considerably higher than the race times of the top ten athletes in these age groups. In difference to trained athletes, which are able to sustain their level of performance up to the age of $\sim 50$ years (33), the age-related performance decline in recreational athletes seems to start at an earlier age. This difference might be due to the fact that recreational athletes have less experience, less mental strength and a lower intensity and volume during training, which are all factors decelerating the decline of age-related performance decline seen in professional athletes $(25,26,41,58)$.

\section{Sex difference in performance across years}

A further important finding was that the sex difference decreased across years for split and overall race times in some age groups (i.e. 25-29, 50-54 and 55-59 years in swimming, 25-29, 45-49 and 65-69 years in cycling, pro athletes and 65-69 years in running and 25-29 and 6569 years for overall time). The decrease in sex difference in the younger age groups is most likely due to the relative improvement of performance of female athletes compared to male athletes during the studied period.

The sex difference in endurance performance is primarily caused by physiological differences in $\mathrm{VO}_{2} \max (19)$ and anthropometric characteristics such as the difference in skeletal muscle mass and body fat (25). It has been shown that female ultra-runners have a lower skeletal muscle mass and a higher percentage of body fat than male ultra-runners, which leads to a disadvantage for women in ultra-running performance $(22,48)$. It has previously been observed that the age-related decline in endurance performance is greater in female compared to male athletes $(6,31,42)$ and an increased sex difference with advancing age has been documented in elite athletes $(31,53)$. 
The decrease in sex difference across years is in accordance with previous studies $(2,54)$. As mentioned above, in the past few years, master athletes such as age group Ironman athletes were able to improve their performance, while the performance of younger athletes remained stable. In the last years, female master athletes had a greater progression of athletic performance than their male counterparts $(2,54)$, which leads to the decreased sex difference in these age groups.

The sex difference in performance could also be due to environmental conditions. In 'Isklar Norseman Xtreme Triathlon' held as an Ironman-distance triathlon at rather low temperatures, the number of successful women increased across years, women achieved a similar performance compared to men in swimming, cycling and overall race time, and women improved their performance in swimming, cycling and overall race time across years (21).

Other reasons for the sex difference in performance could be different changes in body composition in women and men during an Ironman triathlon (38). While male Ironman triathletes loose skeletal muscle mass during an Ironman triathlon (17) mainly due to a depletion of glycogen stores of the lower limbs (38), no change in body mass could be detected in female Ironman triathletes (24).

Pacing strategy is also different between female and male triathletes $(3,20)$. During an Ironman triathlon, a positive pacing strategy was adopted by both elite women and men in both cycling and running, where women were slower in half of the considered cycling splits but not slower in the running splits (3). Also in a longer triathlon race such as 'Ultraman Hawaii', women paced differently where performance in the fastest women and men decreased in the beginning, but improved in men towards the end of the race (20). 
There is also a difference in the contribution of swimming, cycling and running to overall race time. Between 1989 and 2014, swimming and cycling contributions changed in an undulating fashion in the Ironman triathlon where the contribution was inversely between the two segments for both sexes whereas running contribution decreased for men (9).

Furthermore, there is also a difference between women and men regarding the internet-related activities and interest for Ironman triathlon competitions. When Google Trends was used from 2004, triathlon-related internet activities correlated negatively with the number of annual finishers while an increase in participation of female athletes who were less likely to surf the Internet could be noticed. Younger athletes who were more likely to access the web were underrepresented in Ironman triathlon races. And there was a significant and positive correlation between the cycling split times and the internet query volumes especially for male athletes (37).

\section{Implications for training and competing in Ironman triathlon}

The start of the age-related decline in overall race performance is different between women and men. While this decline started women in age group 30-34 years, it started in age group 35-39 years in men. Although the age of peak Ironman triathlon performance in elite athletes is very similar at $30-35$ years for both women and men $(8,21,47)$, female triathletes intending to achieve their best Ironman race time should change from the shorter triathlon distances to the Ironman distance $\sim 5$ years earlier than men. In absolute numbers, women should start competing in Ironman triathlon before the age of 30 years and men before the age of 35 years to achieve their best Ironman race time. 


\section{Strength, weakness, limitations and implications for future research}

The strength of this study is the large data set including all finishers of all Ironman races held worldwide between 2002 and 2015, where a total 329,066 male and 81,815 female finishers in 253 Ironman races were analysed, with a dropout of only $~ 5 \%$. However, some races might not have been documented in the official Ironman website but the largest Ironman races were all listed. A weakness is that we were not able to consider environmental and geographic conditions for these races.

This cross-sectional, retrospective data analysis suffers some limitations since the studied period of 14 years is relatively short compared to studies investigating the same subject (10, 32). Additionally, individual factors of endurance performance such as physiological $(39,49)$, anthropometric $(13,25)$ and demographic characteristics $(14)$, as well as training regimes (11, $25)$, motivation $(12,16,28)$ and previous race experience $(25)$ could not be taken into consideration. Also, the influences of environmental conditions of the races were unknown (7, $8,52,59,60)$. Future studies would need to include the aspect of environmental conditions since this aspect seems to a have an influence on pacing (1).

\section{PRACTIAL APPLICATIONS}

For athletes and coaches, the participation of age group athletes in Ironman triathlon increased for both sexes, women reduced the sex difference in some age groups across years and the age-related decline in performance started at 25-29 years in swimming and 30-34 and 35-39 years in cycling, running and overall race time, depending upon the sex. This observation is of great practical importance for athletes and coaches working with master triathletes, who are encouraged to manage the relatively early age-related decrease in swimming performance. Although swimming, cycling and running splits are considered as endurance exercise, each of them correlate differently with anthropometry. A decline in muscle mass with aging might 
affect performance in swimming more than in the other two splits. For instance, an athlete with reduced muscle mass is expected to decrease running performance (where they carry less mass through distance) in a lesser degree than in swimming, where body mass is "supported" by water. Thus, athletes older than 30 years should optimize their training (e.g. including strength training for muscle hypertrophy) and nutrition (e.g. adequate protein intake) in order to maintain their muscle mass targeting swimming performance. This age-related performance decline starts earlier than reported in existing studies and is most likely due to the inclusion of all athletes per age group instead of only the top ten athletes per age group in earlier studies. The age-related performance decline in recreational compared to professional athletes seems to start at an earlier age. This difference might be due to the fact that recreational athletes have less experience, mental strength and a lower intensity and volume of training, which are all factors to decelerate the decline of age-related performance decline seen in professional athletes. In order to be able to preserve the level of competition in recreational athletes until the age of $\sim 50$ years, these factors are of major importance to the athletes and coaches and should be included in the planning of a recreational triathlon athlete's career. These findings show that ageing recreational athletes might benefit the most of an increased training intensity and volume in the swimming split discipline in order to reduce the gap to professional athletes. Therefore athletes should increase their training regime in the swimming split discipline in relation to the other split disciplines as they age in order to achieve an optimal performance improvement. Taken all together, women should start competing in Ironman triathlon before the age of 30 years and men before the age of 35 years in order to achieve their best Ironman race time. 


\section{References}

1. Abbiss CR and Laursen PB. Describing and understanding pacing strategies during athletic competition. Sports Medicine 38: 239-252, 2008.

2. Akkari A, Machin D, and Tanaka H. Greater progression of athletic performance in older Masters athletes. Age and Ageing 44: 683-686, 2015.

3. Angehrn N, Rüst CA, Nikolaidis PT, Rosemann T, and Knechtle B. Positive pacing in elite IRONMAN triathletes. Chinese Journal of Physiology 2016 Dec 31;59(6). pii: CJP.2016.BAE418. doi: 10.4077/CJP.2016.BAE418. [Epub ahead of print]

4. Bentley DJ, Millet GP, Vleck VE, and McNaughton LR. Specific aspects of contemporary triathlon: Implications for physiological analysis and performance. Sports Medicine 32: 345-359, 2002.

5. Bernard T, Sultana F, Lepers R, Hausswirth C, and Brisswalter J. Age-related decline in olympic triathlon performance: Effect of locomotion mode. Experimental Aging Research 36: 64-78, 2010.

6. Donato AJ, Tench K, Glueck DH, Seals DR, Eskurza I, and Tanaka H. Declines in physiological functional capacity with age: A longitudinal study in peak swimming performance. Journal of Applied Physiology 94: 764-769, 2003.

7. El Helou N, Tafflet M, Berthelot G, Tolaini J, Marc A, Guillaume M, Hausswirth C, and Toussaint JF. Impact of environmental parameters on Marathon running performance. PLoS ONE 7, 2012.

8. Ely MR, Cheuvront SN, Roberts WO, and Montain SJ. Impact of weather on marathon-running performance. Medicine and Science in Sports and Exercise 39: 487493, 2007.

9. Figueiredo P, Marques EA, and Lepers R. Changes in contributions of swimming, cycling, and running performances on overall triathlon performance over a 26-year period. Journal of Strength and Conditioning Research 30: 2406-2415, 2016. 
10. Gallmann D, Knechtle B, Rüst CA, Rosemann T, and Lepers R. Elite triathletes in 'Ironman Hawaii' get older but faster. Age 36: 407-416, 2014.

11. Gulbin JP and Gaffney PT. Ultraendurance triathlon participation: Typical race preparation of lower level triathletes. Journal of Sports Medicine and Physical Fitness 39: $12-15,1999$.

12. Hodge K, Allen JB, and Smellie L. Motivation in Masters sport: Achievement and social goals. Psychology of Sport and Exercise 9: 157-176, 2008.

13. Hoffman MD. Anthropometric characteristics of ultramarathoners. International Journal of Sports Medicine 29: 808-811, 2008.

14. Hoffman MD and Fogard K. Demographic characteristics of 161-km ultramarathon runners. Research in Sports Medicine 20: 59-69, 2012.

15. Hoffman MD and Wegelin JA. The western states 100-mile endurance run: Participation and performance trends. Medicine and Science in Sports and Exercise 41: 2191-2198, 2009.

16. Houston M, Dolan S, and Martin S. The impact of physical, nutritional, and mental preparation on triathlon performance. Journal of Sports Medicine and Physical Fitness 51: 583-594, 2011.

17. Knechtle B, Baumann B, Wirth A, Knechtle P, and Rosemann T. Male ironman triathletes lose skeletal muscle mass. Asia Pacific Journal of Clinical Nutrition 19: 9197, 2010.

18. Knechtle B, Knechtle P, and Lepers R. Participation and performance trends in ultratriathlons from 1985 to 2009. Scandinavian Journal of Medicine and Science in Sports 21: e82-90, 2011.

19. Knechtle B, Müller C, Willmann F, Kotteck K, Eser P, and Knecht H. Fat oxidation in men and women endurance athletes in running and cycling. International Journal of Sports Medicine 25: 38-44, 2004. 
20. Knechtle B and Nikolaidis PT. Sex differences in pacing during 'Ultraman Hawaii'. PeerJ 4: e2509, 2016.

21. Knechtle B, Nikolaidis PT, Stiefel M, Rosemann T, and Rüst CA. Performance and sex differences in 'Isklar Norseman Xtreme Triathlon'. Chinese Journal of Physiology 59: 276-283, 2016.

22. Knechtle B, Rüst CA, Rosemann T, and Lepers R. Age-related changes in 100-km ultra-marathon running performance. Age 34: 1033-1045, 2012.

23. Knechtle B, Valeri F, Zingg MA, Rosemann T, and Rüst CA. What is the age for the fastest ultra-marathon performance in time-limited races from $6 \mathrm{~h}$ to 10 days? Age 36, 2014.

24. Knechtle B, Wirth A, Baumann B, Knechtle P, Kohler G, Rosemann T, and Senn O. An ironman triathlon does not lead to a change in body mass in female triathletes. Research in Sports Medicine 18: 115-126, 2010.

25. Knechtle B, Wirth A, Baumann B, Knechtle P, and Rosemann T. Personal best time, percent body fat, and training are differently associated with race time for male and female lronman triathletes. Research Quarterly for Exercise and Sport 81: 62-68, 2010.

26. Knechtle B, Wirth A, and Rosemann T. Predictors of race time in male Ironman triathletes: Physical characteristics, training, or prerace experience? Perceptual and Motor Skills 111: 437-446, 2010.

27. Knechtle R, Rüst CA, Rosemann T, and Knechtle B. The best triathletes are older in longer race distances - a comparison between Olympic, Half-Ironman and Ironman distance triathlon. SpringerPlus 3, 2014.

28. Krouse RZ, Ransdell LB, Lucas SM, and Pritchard ME. Motivation, goal orientation, coaching, and training habits of women ultrarunners. Journal of Strength and Conditioning Research 25: 2835-2842, 2011. 
29. Lepers R. Analysis of Hawaii Ironman performances in elite triathletes from 1981 to 2007. Medicine and Science in Sports and Exercise 40: 1828-1834, 2008.

30. Lepers R, Knechtle B, and Stapley PJ. Trends in triathlon performance: Effects of sex and age. Sports Medicine 43: 851-863, 2013.

31. Lepers R and Maffiuletti NA. Age and gender interactions in ultraendurance performance: insight from the triathlon. Medicine and Science in Sports and Exercise 43: 134-139, 2011.

32. Lepers R, Rüst CA, Stapley PJ, and Knechtle B. Relative improvements in endurance performance with age: Evidence from 25 years of Hawaii Ironman racing. Age 35: 953-962, 2013.

33. Lepers R, Sultana F, Bernard T, Hausswirth C, and Brisswalter J. Age-related changes in triathlon performances. International Journal of Sports Medicine 31: 251-256, 2010.

34. Leyk D, Erley O, Gorges W, Ridder D, Rüther T, Wunderlich M, Sievert A, Essfeld D, Piekarski C, and Erren T. Performance, training and lifestyle parameters of marathon runners aged 2080 years: Results of the PACE-study. International Journal of Sports Medicine 30: 360-365, 2009.

35. Leyk D, Erley O, Ridder D, Leurs M, Rüther T, Wunderlich M, Sievert A, Baum K, and Essfeld D. Age-related changes in marathon and half-marathon performances. International Journal of Sports Medicine 28: 513-517, 2007.

36. McKean KA, Manson NA, and Stanish WD. Musculoskeletal injury in the masters runners. Clinical Journal of Sport Medicine 16: 149-154, 2006.

37. Mnadla S, Bragazzi NL, Rouissi M, Chaalali A, Siri A, Padulo J, Ardigo LP, Brigo F, Chamari K, and Knechtle B. Infodemiological data of Ironman Triathlon in the study period 2004-2013. Data Brief 9: 123-127, 2016. 
38. Mueller SM, Anliker E, Knechtle P, Knechtle B, and Toigo M. Changes in body composition in triathletes during an Ironman race. European Journal of Applied Physiology 113: 2343-2352, 2013.

39. O'Toole ML, Douglas B. Hiller W, Crosby LO, and Douglas PS. The ultraendurance triathlete: A physiological profile. Medicine and Science in Sports and Exercise 19: 45-50, 1987.

40. Ortega FB, Artero EG, Ruiz JR, España-Romero V, Jiménez-Pavón D, VicenteRodriguez G, Moreno LA, Manios Y, Béghin L, Ottevaere C, Ciarapica D, Sarri K, Dietrich S, Blair SN, Kersting M, Molnar D, González-Gross M, Gutiérrez A, Sjöström M, and Castillo MJ. Physical fitness levels among European adolescents: The HELENA study. British Journal of Sports Medicine 45: 20-29, 2011.

41. Parry D, Chinnasamy C, Papadopoulou E, Noakes T, and Micklewright D. Cognition and performance: Anxiety, mood and perceived exertion among Ironman triathletes. British Journal of Sports Medicine 45: 1088-1094, 2011.

42. Ransdell LB, Vener J, and Huberty J. Masters athletes: An analysis of running, swimming and cycling performance by age and gender. Journal of Exercise Science and Fitness 7: S61-S73, 2009.

43. Reaburn P and Dascombe B. Endurance performance in masters athletes. European Review of Aging and Physical Activity 5: 31-42, 2008.

44. Robinson S. Experimental studies of physical fitness in relation to age. Arbeitsphysiologie 10: 251-323, 1938.

45. RÜst CA, Knechtle B, Knechtle P, Rosemann T, and Lepers R. Age of peak performance in elite male and female Ironman triathletes competing in Ironman Switzerland, a qualifier for the Ironman world championship, Ironman Hawaii, from 1995 to 2011. Open Access Journal of Sports Medicine 3: 175-182, 2012. 
46. Rüst CA, Knechtle B, Knechtle P, Rosemann T, and Lepers R. Participation and performance trends in triple iron ultra-triathlon - A cross-sectional and longitudinal data analysis. Asian Journal of Sports Medicine 3: 145-152, 2012.

47. Rüst CA, Knechtle B, Rosemann T, and Lepers R. Sex difference in race performance and age of peak performance in the Ironman Triathlon World Championship from 1983 to 2012. Extreme Physiology and Medicine 1, 2012.

48. Rüst CA, Rosemann T, Zingg MA, and Knechtle B. Age group performances in 100 km and 100 miles ultra-marathons. SpringerPlus 3: 1-11, 2014.

49. Saunders PU, Pyne DB, Telford RD, and Hawley JA. Factors affecting running economy in trained distance runners. Sports Medicine 34: 465-485, 2004.

50. Schulz R and Curnow C. Peak performance and age among superathletes: Track and field, swimming, baseball, tennis, and golf. Journals of Gerontology 43: P113- P120, 1988.

51. Shaw KL and Ostrow A. Motivation and psychological skills in the senior athlete. European Review of Aging and Physical Activity 2: 22-34, 2005.

52. Sparks SA, Cable NT, Doran DA, and Maclaren DPM. The influence of environmental temperature on duathlon performance. Ergonomics 48: 1558-1567, 2005

53. Stevenson JL, Song H, and Cooper JA. Age and sex differences pertaining to modes of locomotion in triathlon. Medicine and Science in Sports and Exercise 45: 976-984, 2013.

54. Stiefel M, Knechtle B, and Lepers R. Master triathletes have not reached limits in their Ironman triathlon performance. Scandinavian Journal of Medicine and Science in Sports 24: 89-97, 2014. 
55. Stiefel M, Knechtle B, Rüst CA, Rosemann T, and Lepers R. The age of peak performance in Ironman triathlon: A cross-sectional and longitudinal data analysis. Extreme Physiology and Medicine 2: 27, 2013.

56. Stiefel M, Rüst CA, Rosemann T, and Knechtle B. A comparison of participation and performance in age-group finishers competing in and qualifying for Ironman Hawaii. International Journal of General Medicine 6: 67-77, 2013

57. Sultana F, Brisswalter J, Lepers R, Hausswirth C, and Bernard T. Effects of age and gender on Olympic triathlon performances. Science and Sports 23: 130-135, 2008.

58. Tanaka H and Seals DR. Endurance exercise performance in Masters athletes: Ageassociated changes and underlying physiological mechanisms. Journal of Physiology 586: 55-63, 2008.

59. Vihma T. Effects of weather on the performance of marathon runners. International Journal of Biometeorology 54: 297-306, 2010.

60. Wegelin JA and Hoffman MD. Variables associated with odds of finishing and finish time in a 161-km ultramarathon. European Journal of Applied Physiology 111: 145$153,2011$.

61. Wu SSW, Peiffer JJ, Brisswalter J, Lau WY, Nosaka K, and Abbiss CR. Influence of race distance and biological sex on age-related declines in triathlon performance. Part A. Journal of Science and Cycling 3: 42-48, 2014.

\section{Figure captions}

Figure 1 Race time in swimming, cycling, running and overall race by sex and age group. Women are depicted by $\boldsymbol{\Lambda}$ and men by 
Table 1: Included races, sorted by continent

\begin{tabular}{|c|c|c|}
\hline Ironman & Included editions & Excluded editions \\
\hline Canada & 2004-2006, 2008-2015 & 2007 \\
\hline Muskoka & 2015 & \\
\hline Coeur d'Alene & $2003,2005-2015$ & 2004 \\
\hline Lake Tahoe & 2013,2015 & 2014 \\
\hline Boulder & 2014-2015 & \\
\hline Arizona & $2005-2015$ & \\
\hline Los Cabos & 2013-2015 & \\
\hline Hawaii & $2003-2015$ & \\
\hline Wisconsin & $2002-2015$ & \\
\hline Mont-Tremblant & 2012-2015 & \\
\hline Lake Placid & 2003-2015 & \\
\hline Maryland & 2014-2015 & \\
\hline Louisville & $2008-2015$ & \\
\hline Chattanooga & 2014-2015 & \\
\hline Florida & $2002-2015$ & \\
\hline Texas & $2008-2015$ & \\
\hline Cozumel & 2009-2015 & \\
\hline Fortaleza & 2014-2015 & \\
\hline Brazil & 2006-2010, 2012-2015 & 2011 \\
\hline Lanzarote & $2011-2015$ & \\
\hline Wales & 2011-2015 & \\
\hline UK & $2010-2015$ & \\
\hline Sweden & $2012-2015$ & \\
\hline Maastricht-Limbur & 2015 & \\
\hline Copenhagen & $2013-2015$ & \\
\hline Frankfurt & $2005,2009-2015$ & 2006-2008 \\
\hline Switzerland & $2011-2015$ & \\
\hline Austria & $2005-2015$ & \\
\hline France & $2005-2015$ & \\
\hline Vichy & 2015 & \\
\hline Mallorca & 2014-2015 & \\
\hline Barcelona & 2014-2015 & \\
\hline South Africa & 2012-2015 & \\
\hline Japan & $2013-2015$ & \\
\hline Taiwan & 2015 & \\
\hline Malaysia & 2006-2008, 2014, 2015 & 2009-2013 \\
\hline Cairns & $2012-2015$ & \\
\hline Australia & $2005-2015$ & \\
\hline Melbourne & $2012-2015$ & \\
\hline Western Australia & $2010-2015$ & \\
\hline New Zealand & $2003-2015$ & \\
\hline Total & 253 & 12 \\
\hline
\end{tabular}


Table 2: Participation across calendar years for all age groups

\begin{tabular}{|c|c|c|c|c|c|c|c|c|c|c|c|c|c|c|c|c|}
\hline & 2002 & 2003 & 2004 & 2005 & 2006 & 2007 & 2008 & 2009 & 2010 & 2011 & 2012 & 2013 & 2014 & 2015 & $\mathbf{r}^{2}$ & $\mathbf{p}$ \\
\hline \multicolumn{17}{|l|}{ Women } \\
\hline Pro & 24 & 106 & 111 & 166 & 178 & 181 & 208 & 216 & 207 & 210 & 264 & 349 & 364 & 304 & 0.88 & $<0.0001$ \\
\hline $18-24$ & 31 & 82 & 113 & 140 & 150 & 136 & 190 & 150 & 148 & 166 & 180 & 226 & 252 & 276 & 0.84 & $<0.0001$ \\
\hline $25-29$ & 114 & 265 & 356 & 540 & 499 & 529 & 715 & 709 & 799 & 732 & 851 & 915 & 990 & 968 & 0.94 & $<0.0001$ \\
\hline $30-34$ & 183 & 423 & 603 & 888 & 821 & 789 & 1,022 & 1,118 & 1,155 & 1,343 & 1,593 & 1,662 & 1,739 & 1,837 & 0.97 & $<0.0001$ \\
\hline $35-39$ & 146 & 395 & 468 & 778 & 779 & 770 & 1,145 & 1,178 & 1,295 & 1,404 & 1,574 & 1,731 & 1,929 & 1,993 & 0.99 & $<0.0001$ \\
\hline $40-44$ & 124 & 297 & 398 & 697 & 680 & 717 & 1,049 & 1,116 & 1,226 & 1,497 & 1,702 & 1,865 & 1,899 & 2,239 & 0.98 & $<0.0001$ \\
\hline $45-49$ & 58 & 148 & 230 & 396 & 429 & 421 & 719 & 828 & 921 & 1,039 & 1,215 & 1,352 & 1,529 & 1,849 & 0.97 & $<0.0001$ \\
\hline $55-59$ & 11 & 30 & 46 & 65 & 69 & 72 & 110 & 141 & 186 & 201 & 267 & 355 & 400 & 513 & 0.89 & $<0.0001$ \\
\hline $60-64$ & & 21 & 15 & 32 & 19 & 28 & 46 & 44 & 59 & 70 & 108 & 96 & 143 & 177 & 0.86 & $<0.0001$ \\
\hline $65-69$ & & 2 & 4 & 12 & 6 & 7 & 7 & 11 & 13 & 25 & 28 & 35 & 36 & 41 & 0.87 & $<0.0001$ \\
\hline $70-74$ & & & 1 & 1 & 3 & 2 & 1 & 1 & & 3 & 2 & 2 & 4 & 11 & 0.42 & 0.0127 \\
\hline $75-79$ & & & & 2 & 1 & & 1 & 1 & 1 & 1 & 2 & 1 & & & 0.02 & 0.6042 \\
\hline \multicolumn{17}{|l|}{ Men } \\
\hline Pro & 45 & 185 & 172 & 293 & 277 & 306 & 412 & 379 & 356 & 375 & 481 & 586 & 583 & 505 & 0.88 & $<0.0001$ \\
\hline $18-24$ & 91 & 245 & 258 & 481 & 408 & 512 & 610 & 565 & 698 & 680 & 786 & 941 & 1,084 & 1,072 & 0.96 & $<0.0001$ \\
\hline $25-29$ & 343 & 716 & 704 & 1349 & 1310 & 1,376 & 1,769 & 1,869 & 2,216 & 2,340 & 2,829 & 3,145 & 3,655 & 3,525 & 0.97 & $<0.0001$ \\
\hline $35-39$ & 587 & 1,501 & 1,798 & 3,464 & 3,270 & 3,567 & 4,586 & 4,752 & 5,261 & 5,308 & 6,708 & 7,326 & 8,483 & 8,545 & 0.97 & $<0.0001$ \\
\hline $40-44$ & 501 & 1,289 & 1,534 & 3,172 & 2,792 & 3,306 & 4,240 & 5,025 & 5,542 & 6,341 & 7,893 & 9,047 & 10,135 & 10,250 & 0.97 & $<0.0001$ \\
\hline $45-49$ & 261 & 777 & 972 & 1,787 & 1,801 & 1,921 & 2,817 & 3,406 & 3,836 & 4,413 & 5,564 & 6,704 & 7,576 & 8,575 & 0.95 & $<0.0001$ \\
\hline $50-54$ & 162 & 421 & 531 & 954 & 881 & 1,007 & 1,594 & 1,900 & 2,207 & 2,508 & 3,359 & 4,155 & 4,715 & 5,501 & 0.92 & $<0.0001$ \\
\hline $55-59$ & 84 & 216 & 277 & 457 & 441 & 488 & 732 & 794 & 909 & 1046 & 1,397 & 1,657 & 2,000 & 2,247 & 0.93 & $<0.0001$ \\
\hline $60-64$ & 30 & 86 & 135 & 172 & 191 & 189 & 333 & 355 & 396 & 498 & 547 & 714 & 839 & 862 & 0.95 & $<0.0001$ \\
\hline $65-69$ & 9 & 33 & 44 & 81 & 58 & 66 & 103 & 121 & 125 & 151 & 191 & 235 & 258 & 297 & 0.93 & $<0.0001$ \\
\hline $70-74$ & 3 & 18 & 10 & 21 & 28 & 22 & 38 & 47 & 58 & 65 & 62 & 75 & 88 & 86 & 0.96 & $<0.0001$ \\
\hline $75-79$ & & 1 & 6 & 9 & 10 & 8 & 9 & 6 & 6 & 12 & 16 & 14 & 15 & 21 & 0.76 & $<0.0001$ \\
\hline
\end{tabular}


Table 3 Split and overall race times for women by age group, times are expressed as h:min

\begin{tabular}{|c|c|c|c|c|c|c|c|c|c|c|c|c|c|c|}
\hline & 2002 & 2003 & 2004 & 2005 & 2006 & 2007 & 2008 & 2009 & 2010 & 2011 & 2012 & 2013 & 2014 & 2015 \\
\hline \multicolumn{15}{|l|}{ Swimming } \\
\hline Pro & 01:04 & 00:58 & $00: 59$ & 01:00 & 01:01 & $00: 59$ & 01:01 & 01:00 & $00: 59$ & 00:59 & 01:01 & $00: 59$ & 00:59 & $00: 59$ \\
\hline $18-24$ & 01:09 & 01:11 & 01:12 & $01: 14$ & $01: 15$ & $01: 14$ & $01: 14$ & $01: 16$ & $01: 14$ & $01: 13$ & 01:18 & $01: 17$ & $01: 17$ & 01:14 \\
\hline $25-29$ & 01:18 & 01:13 & 01:14 & 01:14 & 01:16 & $01: 15$ & 01:16 & 01:17 & 01:15 & 01:16 & 01:19 & 01:17 & 01:17 & $01: 17$ \\
\hline $30-34$ & 01:18 & $01: 15$ & $01: 16$ & $01: 16$ & 01:18 & $01: 17$ & 01:17 & 01:18 & $01: 17$ & 01:18 & 01:21 & 01:20 & 01:19 & $01: 18$ \\
\hline $35-39$ & 01:21 & 01:18 & $01: 18$ & 01:18 & 01:19 & 01:21 & 01:21 & 01:21 & 01:20 & $01: 21$ & $01: 23$ & 01:21 & 01:21 & 01:20 \\
\hline $40-44$ & 01:21 & 01:20 & 01:19 & 01:19 & 01:21 & 01:21 & 01:22 & $01: 23$ & 01:22 & 01:22 & $01: 25$ & $01: 23$ & 01:22 & $01: 21$ \\
\hline $45-49$ & $01: 28$ & $01: 22$ & 01:22 & $01: 22$ & $01: 25$ & $01: 24$ & $01: 23$ & $01: 24$ & $01: 23$ & $01: 25$ & $01: 26$ & $01: 24$ & $01: 24$ & $01: 23$ \\
\hline $50-54$ & $01: 33$ & $01: 23$ & $01: 26$ & $01: 25$ & $01: 27$ & $01: 25$ & $01: 27$ & $01: 27$ & $01: 25$ & $01: 25$ & $01: 27$ & $01: 26$ & $01: 25$ & $01: 24$ \\
\hline $55-59$ & 01:39 & $01: 27$ & 01:32 & 01:30 & 01:34 & 01:31 & 01:28 & 01:29 & 01:28 & 01:28 & 01:31 & 01:28 & 01:27 & $01: 24$ \\
\hline $60-64$ & & $01: 33$ & 01:32 & $01: 34$ & 01:37 & $01: 33$ & 01:30 & $01: 34$ & 01:30 & $01: 35$ & $01: 33$ & $01: 34$ & $01: 33$ & $01: 27$ \\
\hline $65-69$ & & $01: 50$ & $01: 52$ & $01: 45$ & $01: 32$ & $01: 40$ & $01: 30$ & 01:40 & $01: 42$ & 01:39 & $01: 40$ & $01: 36$ & $01: 42$ & $01: 29$ \\
\hline $70-74$ & & & $01: 46$ & $01: 58$ & $01: 51$ & $01: 55$ & $01: 53$ & $01: 47$ & & $01: 56$ & $01: 41$ & $01: 54$ & 01:39 & $01: 40$ \\
\hline 75-79 & & & & $01: 36$ & $01: 56$ & & 01:38 & 01:33 & 01:48 & 02:03 & $01: 56$ & $02: 13$ & & \\
\hline \multicolumn{15}{|l|}{ Cycling } \\
\hline Pro & $05: 21$ & $05: 30$ & $05: 41$ & $05: 32$ & $05: 31$ & $05: 30$ & $05: 27$ & $05: 23$ & $05: 22$ & $05: 19$ & $05: 20$ & 05:19 & $05: 18$ & $05: 22$ \\
\hline $18-24$ & $06: 32$ & $06: 39$ & $06: 47$ & $06: 43$ & $06: 49$ & $06: 46$ & $06: 39$ & $06: 41$ & $06: 39$ & $06: 38$ & $06: 45$ & $06: 41$ & $06: 48$ & $06: 47$ \\
\hline $25-29$ & $06: 42$ & $06: 43$ & $06: 43$ & $06: 37$ & $06: 42$ & $06: 42$ & $06: 44$ & $06: 35$ & $06: 40$ & $06: 37$ & $06: 41$ & $06: 39$ & $06: 38$ & $06: 43$ \\
\hline $30-34$ & $06: 36$ & $06: 45$ & $06: 44$ & $06: 39$ & $06: 44$ & $06: 46$ & $06: 41$ & $06: 37$ & $06: 39$ & $06: 38$ & $06: 39$ & $06: 41$ & $06: 41$ & $06: 43$ \\
\hline $35-39$ & $06: 34$ & $06: 46$ & $06: 45$ & $06: 43$ & $06: 45$ & $06: 49$ & $06: 45$ & $06: 40$ & $06: 42$ & $06: 40$ & $06: 42$ & 06:40 & $06: 44$ & 06:42 \\
\hline $40-44$ & $06: 32$ & $06: 47$ & $06: 48$ & $06: 42$ & $06: 47$ & $06: 51$ & $06: 48$ & $06: 43$ & $06: 43$ & $06: 41$ & $06: 45$ & $06: 45$ & $06: 48$ & $06: 47$ \\
\hline $45-49$ & $06: 58$ & $06: 58$ & $06: 55$ & $06: 51$ & $06: 56$ & $06: 55$ & $06: 53$ & $06: 47$ & $06: 49$ & $06: 47$ & $06: 45$ & $06: 47$ & $06: 52$ & $06: 48$ \\
\hline $50-54$ & $06: 45$ & 07:00 & $07: 13$ & 07:00 & 07:03 & 07:02 & 07:05 & $06: 59$ & $06: 54$ & $06: 54$ & $06: 53$ & $06: 56$ & $06: 58$ & $06: 57$ \\
\hline $55-59$ & 07:06 & $06: 57$ & $07: 18$ & 07:08 & 07:20 & $07: 18$ & 07:11 & 07:03 & 07:04 & 07:03 & 07:03 & $06: 59$ & 07:06 & 07:05 \\
\hline $60-64$ & & $07: 31$ & $07: 30$ & $07: 15$ & 07:09 & $07: 27$ & $07: 21$ & $07: 22$ & 07:07 & 07:16 & 07:19 & $07: 16$ & $07: 23$ & $07: 12$ \\
\hline $65-69$ & & $07: 40$ & $07: 58$ & $07: 35$ & $07: 36$ & $07: 59$ & $07: 39$ & $07: 36$ & $07: 25$ & $07: 14$ & $07: 17$ & $07: 11$ & $07: 27$ & $07: 26$ \\
\hline $70-74$ & & & 08:19 & 07:01 & 08:08 & 08:08 & $07: 32$ & $07: 35$ & & 08:06 & $07: 33$ & $07: 55$ & $07: 37$ & $07: 27$ \\
\hline $75-79$ & & & & $07: 28$ & 08:00 & & $08: 22$ & $07: 44$ & 07:34 & 07:44 & 08:06 & 07:38 & & \\
\hline \multicolumn{15}{|l|}{ Running } \\
\hline Pro & $03: 50$ & 03:50 & $03: 43$ & 03:48 & $03: 44$ & $03: 37$ & 03:38 & $03: 35$ & 03:33 & $03: 28$ & 03:30 & $03: 28$ & $03: 26$ & $03: 28$ \\
\hline $18-24$ & $04: 53$ & $05: 13$ & 05:04 & 05:10 & 05:06 & $04: 52$ & $04: 53$ & 05:00 & $04: 58$ & $04: 53$ & 05:01 & 05:02 & 04:59 & 05:03 \\
\hline $25-29$ & $04: 57$ & 05:00 & $04: 56$ & $04: 57$ & $04: 57$ & $04: 53$ & $04: 57$ & 04:55 & $04: 57$ & $04: 51$ & $04: 56$ & $04: 55$ & $04: 48$ & $04: 57$ \\
\hline $30-34$ & 05:02 & 05:01 & 04:59 & 05:02 & 05:05 & $04: 54$ & 04:56 & $04: 55$ & $04: 55$ & $04: 55$ & $04: 53$ & $04: 53$ & $04: 53$ & 04:59 \\
\hline $35-39$ & 05:02 & 05:07 & 05:01 & 05:04 & 05:07 & $04: 57$ & 05:02 & $04: 59$ & $04: 57$ & 05:00 & $04: 59$ & $04: 56$ & $04: 56$ & $04: 59$ \\
\hline $40-44$ & 05:00 & $05: 10$ & 05:04 & 05:04 & 05:09 & 05:01 & 05:06 & 05:06 & $05: 05$ & 05:05 & 05:05 & 05:04 & 05:02 & 05:06 \\
\hline $45-49$ & $05: 18$ & $05: 21$ & 05:09 & $05: 21$ & $05: 21$ & 05:08 & $05: 13$ & 05:11 & $05: 11$ & $05: 12$ & $05: 12$ & $05: 12$ & $05: 14$ & $05: 15$ \\
\hline $50-54$ & $05: 14$ & $05: 27$ & $05: 33$ & $05: 26$ & $05: 33$ & $05: 21$ & $05: 28$ & $05: 26$ & $05: 20$ & $05: 24$ & $05: 22$ & $05: 20$ & $05: 16$ & $05: 22$ \\
\hline $55-59$ & $05: 38$ & $05: 29$ & $05: 36$ & $05: 36$ & $05: 44$ & $05: 33$ & $05: 32$ & $05: 34$ & $05: 26$ & $05: 31$ & $05: 32$ & $05: 28$ & $05: 30$ & $05: 30$ \\
\hline $60-64$ & & $05: 47$ & $05: 32$ & $05: 56$ & 06:03 & $05: 41$ & 05:39 & $05: 47$ & $05: 28$ & $05: 52$ & $05: 42$ & $05: 52$ & $05: 42$ & $05: 46$ \\
\hline $65-69$ & & 06:19 & $06: 13$ & 06:07 & 06:01 & $05: 55$ & $06: 13$ & $06: 13$ & 06:04 & $05: 51$ & $05: 52$ & 06:00 & 06:00 & $06: 12$ \\
\hline $70-74$ & & & $06: 25$ & $05: 14$ & $06: 17$ & $06: 27$ & $06: 35$ & $07: 12$ & & $06: 28$ & $06: 40$ & $06: 05$ & $05: 48$ & $06: 14$ \\
\hline $75-79$ & & & & $06: 50$ & $06: 24$ & & $06: 34$ & 07:14 & 06:39 & $06: 48$ & $06: 24$ & $06: 43$ & & \\
\hline \multicolumn{15}{|l|}{ Overall } \\
\hline Pro & $10: 22$ & $10: 26$ & $10: 30$ & $10: 26$ & $10: 22$ & $10: 12$ & $10: 13$ & $10: 05$ & 10:01 & 09:53 & 09:58 & 09:53 & 09:50 & $09: 56$ \\
\hline $18-24$ & $12: 56$ & $13: 17$ & $13: 18$ & $13: 22$ & $13: 25$ & 13:05 & $12: 58$ & $13: 11$ & 13:05 & $12: 58$ & $13: 18$ & $13: 14$ & $13: 17$ & $13: 20$ \\
\hline $25-29$ & $13: 16$ & $13: 10$ & 13:08 & 13:01 & $13: 11$ & 13:03 & $13: 12$ & 13:01 & 13:06 & $12: 58$ & $13: 10$ & $13: 06$ & $12: 57$ & $13: 13$ \\
\hline $30-34$ & $13: 17$ & $13: 15$ & $13: 14$ & $13: 11$ & $13: 23$ & $13: 12$ & $13: 09$ & $13: 05$ & $13: 07$ & $13: 07$ & $13: 08$ & $13: 10$ & $13: 08$ & $13: 16$ \\
\hline $35-39$ & $13: 16$ & $13: 26$ & $13: 20$ & $13: 21$ & $13: 27$ & $13: 21$ & $13: 24$ & $13: 16$ & $13: 14$ & $13: 18$ & $13: 21$ & $13: 14$ & $13: 17$ & $13: 18$ \\
\hline $40-44$ & $13: 12$ & $13: 34$ & $13: 28$ & $13: 21$ & $13: 33$ & $13: 28$ & $13: 32$ & $13: 28$ & $13: 27$ & $13: 25$ & $13: 32$ & $13: 29$ & $13: 29$ & $13: 32$ \\
\hline $45-49$ & $14: 06$ & $13: 56$ & $13: 43$ & $13: 50$ & $13: 59$ & $13: 41$ & $13: 45$ & $13: 39$ & $13: 41$ & $13: 41$ & $13: 41$ & $13: 41$ & $13: 47$ & $13: 44$ \\
\hline $50-54$ & $13: 53$ & $14: 07$ & $14: 30$ & $14: 08$ & $14: 20$ & $14: 04$ & $14: 17$ & $14: 10$ & $13: 57$ & $14: 01$ & $14: 00$ & $14: 01$ & $13: 57$ & $14: 02$ \\
\hline $55-59$ & $14: 42$ & $14: 07$ & $14: 44$ & $14: 31$ & $14: 56$ & $14: 37$ & $14: 29$ & $14: 24$ & $14: 15$ & $14: 20$ & $14: 25$ & $14: 13$ & $14: 21$ & $14: 19$ \\
\hline $60-64$ & & $15: 04$ & $14: 49$ & $15: 03$ & $15: 05$ & $14: 57$ & $14: 47$ & $15: 02$ & $14: 23$ & $15: 02$ & $14: 53$ & $15: 01$ & $14: 57$ & $14: 45$ \\
\hline $65-69$ & & $16: 12$ & $16: 21$ & $15: 47$ & $15: 30$ & $15: 53$ & $15: 42$ & $15: 49$ & $15: 25$ & $15: 01$ & $15: 05$ & $15: 07$ & $15: 27$ & $15: 28$ \\
\hline $70-74$ & & & $16: 55$ & $14: 30$ & $16: 35$ & $16: 39$ & $16: 17$ & $16: 53$ & & $16: 53$ & $16: 09$ & $16: 15$ & $15: 21$ & $15: 38$ \\
\hline $75-79$ & & & & $16: 20$ & $16: 59$ & & $17: 02$ & $16: 54$ & $16: 20$ & $16: 56$ & $16: 51$ & $16: 56$ & & \\
\hline
\end{tabular}


Table 4 Split and overall race times for men by age group, times are expressed as h:min

\begin{tabular}{|c|c|c|c|c|c|c|c|c|c|c|c|c|c|c|}
\hline & 2002 & 2003 & 2004 & 2005 & 2006 & 2007 & 2008 & 2009 & 2010 & 2011 & 2012 & 2013 & 2014 & 2015 \\
\hline \multicolumn{15}{|c|}{ Swimming } \\
\hline Pro & $00: 57$ & $00: 54$ & $00: 54$ & $00: 54$ & $00: 55$ & $00: 56$ & $00: 55$ & $00: 54$ & $00: 53$ & $00: 54$ & $00: 54$ & $00: 54$ & $00: 54$ & $00: 54$ \\
\hline $18-24$ & 01:11 & 01:09 & 01:09 & 01:09 & 01:11 & 01:11 & $01: 13$ & $01: 14$ & $01: 12$ & 01:12 & $01: 14$ & $01: 13$ & $01: 14$ & 01:14 \\
\hline $25-29$ & $01: 13$ & 01:09 & 01:09 & 01:09 & 01:10 & 01:10 & $01: 12$ & $01: 13$ & $01: 12$ & $01: 13$ & $01: 16$ & $01: 14$ & $01: 14$ & $01: 14$ \\
\hline $30-34$ & $01: 15$ & 01:10 & 01:11 & $01: 10$ & $01: 12$ & $01: 12$ & $01: 13$ & $01: 13$ & $01: 12$ & $01: 13$ & $01: 16$ & $01: 15$ & $01: 15$ & $01: 15$ \\
\hline $35-39$ & $01: 16$ & 01:12 & 01:12 & $01: 12$ & $01: 14$ & $01: 14$ & $01: 15$ & $01: 15$ & $01: 14$ & $01: 14$ & $01: 17$ & $01: 16$ & $01: 15$ & $01: 16$ \\
\hline $40-44$ & 01:18 & $01: 14$ & $01: 14$ & $01: 14$ & $01: 15$ & $01: 15$ & $01: 16$ & $01: 16$ & $01: 16$ & $01: 16$ & 01:18 & $01: 17$ & $01: 17$ & $01: 17$ \\
\hline $45-49$ & $01: 21$ & $01: 16$ & $01: 16$ & $01: 16$ & $01: 18$ & $01: 17$ & $01: 18$ & $01: 17$ & $01: 17$ & $01: 18$ & $01: 20$ & $01: 18$ & $01: 18$ & $01: 18$ \\
\hline $50-54$ & $01: 23$ & 01:19 & 01:20 & $01: 18$ & $01: 21$ & 01:20 & $01: 19$ & 01:20 & 01:20 & 01:20 & 01:22 & 01:20 & 01:20 & 01:20 \\
\hline $55-59$ & $01: 27$ & $01: 21$ & $01: 23$ & $01: 22$ & $01: 24$ & $01: 22$ & $01: 22$ & $01: 23$ & 01:22 & $01: 23$ & $01: 25$ & $01: 23$ & $01: 22$ & $01: 22$ \\
\hline $60-64$ & $01: 32$ & $01: 26$ & $01: 29$ & $01: 26$ & $01: 29$ & $01: 26$ & $01: 26$ & $01: 27$ & $01: 27$ & $01: 26$ & $01: 29$ & $01: 26$ & $01: 25$ & $01: 23$ \\
\hline $65-69$ & $01: 29$ & $01: 34$ & 01:35 & $01: 33$ & $01: 36$ & $01: 35$ & $01: 31$ & $01: 33$ & $01: 31$ & 01:31 & 01:33 & $01: 32$ & 01:31 & $01: 28$ \\
\hline $70-74$ & 01:39 & $01: 34$ & 01:32 & $01: 42$ & 01:37 & $01: 37$ & $01: 38$ & 01:39 & $01: 34$ & $01: 36$ & $01: 37$ & $01: 36$ & $01: 32$ & $01: 35$ \\
\hline $75-79$ & & 01:44 & 01:44 & 01:52 & 01:41 & 01:51 & 01:42 & 01:46 & 01:36 & 01:40 & 01:40 & 01:38 & 01:44 & 01:34 \\
\hline \multicolumn{15}{|l|}{ Cycling } \\
\hline Pro & 05:08 & 05:00 & $05: 11$ & $04: 57$ & $04: 58$ & 05:00 & $04: 57$ & $04: 56$ & $04: 51$ & $04: 50$ & $04: 50$ & $04: 52$ & $04: 53$ & $04: 53$ \\
\hline $18-24$ & 06:10 & $06: 12$ & $06: 15$ & 06:05 & 06:11 & $06: 15$ & $06: 13$ & 06:07 & 06:11 & $06: 15$ & 06:19 & $06: 13$ & $06: 18$ & $06: 19$ \\
\hline $25-29$ & $06: 06$ & $06: 05$ & $06: 05$ & 05:59 & 06:08 & 06:01 & $06: 02$ & $05: 59$ & 06:04 & 06:08 & $06: 13$ & 06:08 & $06: 11$ & $06: 14$ \\
\hline $30-34$ & 06:04 & 06:04 & 06:07 & 06:00 & 06:05 & 06:05 & 06:02 & $05: 58$ & 06:02 & 06:04 & $06: 07$ & 06:05 & 06:09 & $06: 11$ \\
\hline $35-39$ & $06: 03$ & 06:09 & 06:07 & 06:02 & 06:09 & $06: 10$ & $06: 05$ & 06:01 & $06: 05$ & $06: 05$ & 06:07 & $06: 07$ & 06:08 & $06: 10$ \\
\hline $40-44$ & $06: 10$ & $06: 14$ & $06: 16$ & 06:07 & $06: 13$ & $06: 13$ & 06:09 & $06: 05$ & 06:09 & 06:09 & $06: 11$ & $06: 10$ & $06: 13$ & $06: 14$ \\
\hline $45-49$ & $06: 16$ & $06: 20$ & $06: 21$ & $06: 16$ & $06: 20$ & $06: 20$ & $06: 16$ & $06: 10$ & $06: 12$ & $06: 14$ & $06: 15$ & $06: 14$ & $06: 16$ & $06: 18$ \\
\hline $50-54$ & $06: 26$ & $06: 34$ & $06: 33$ & $06: 25$ & $06: 31$ & $06: 29$ & $06: 24$ & $06: 19$ & $06: 22$ & $06: 21$ & $06: 23$ & $06: 23$ & $06: 24$ & $06: 25$ \\
\hline $55-59$ & $06: 37$ & $06: 38$ & $06: 43$ & $06: 39$ & $06: 44$ & $06: 40$ & $06: 36$ & $06: 31$ & $06: 30$ & $06: 32$ & $06: 31$ & $06: 35$ & $06: 33$ & $06: 34$ \\
\hline $60-64$ & $06: 34$ & $06: 48$ & $06: 55$ & $06: 44$ & $06: 52$ & $06: 51$ & $06: 44$ & $06: 47$ & $06: 47$ & $06: 44$ & $06: 46$ & $06: 44$ & $06: 46$ & $06: 44$ \\
\hline $65-69$ & $06: 36$ & 07:00 & $07: 18$ & $06: 56$ & $06: 57$ & $07: 10$ & $06: 56$ & $06: 59$ & $06: 55$ & $06: 57$ & $06: 58$ & $06: 56$ & $07: 05$ & $06: 55$ \\
\hline $70-74$ & 07:01 & 07:19 & $07: 44$ & $07: 22$ & 07:07 & $07: 26$ & $07: 22$ & $07: 14$ & 07:06 & $07: 13$ & 07:19 & 07:09 & 07:19 & $07: 16$ \\
\hline 75-79 & & 07:38 & 07:21 & 07:22 & $07: 34$ & $07: 36$ & 07:39 & 07:31 & 07:22 & 07:31 & 07:30 & 07:28 & $07: 14$ & 07:24 \\
\hline \multicolumn{15}{|c|}{ Running } \\
\hline Pro & $03: 26$ & 03:28 & 03:22 & $03: 25$ & $03: 22$ & 03:19 & $03: 24$ & $03: 23$ & $03: 15$ & $03: 16$ & 03:21 & $03: 16$ & $03: 16$ & 03:19 \\
\hline $18-24$ & 04:40 & $04: 56$ & $04: 47$ & $04: 50$ & $04: 47$ & $04: 46$ & 04:50 & $04: 50$ & $04: 43$ & $04: 46$ & $04: 48$ & $04: 45$ & $04: 47$ & $04: 50$ \\
\hline $25-29$ & $04: 44$ & $04: 45$ & $04: 38$ & $04: 42$ & 04:40 & 04:29 & $04: 36$ & $04: 35$ & $04: 37$ & $04: 37$ & 04:39 & $04: 37$ & $04: 37$ & $04: 43$ \\
\hline $30-34$ & $04: 43$ & $04: 46$ & $04: 43$ & $04: 42$ & $04: 42$ & $04: 35$ & $04: 38$ & $04: 34$ & $04: 33$ & $04: 33$ & $04: 35$ & $04: 33$ & $04: 35$ & $04: 40$ \\
\hline $35-39$ & $04: 45$ & $04: 50$ & $04: 42$ & $04: 45$ & $04: 46$ & $04: 39$ & $04: 41$ & $04: 38$ & $04: 40$ & $04: 37$ & $04: 38$ & $04: 38$ & $04: 37$ & $04: 41$ \\
\hline $40-44$ & $04: 49$ & $04: 52$ & $04: 50$ & 04:48 & 04:51 & $04: 44$ & $04: 45$ & $04: 44$ & $04: 44$ & $04: 43$ & $04: 45$ & $04: 43$ & 04:44 & $04: 48$ \\
\hline $45-49$ & 05:02 & 05:04 & $04: 57$ & 05:00 & $04: 58$ & $04: 53$ & $04: 53$ & $04: 50$ & 04:49 & 04:49 & $04: 51$ & $04: 50$ & $04: 50$ & $04: 56$ \\
\hline $50-54$ & $05: 13$ & $05: 12$ & 05:06 & $05: 10$ & $05: 10$ & 05:02 & 05:00 & 05:02 & 05:01 & 05:00 & 05:02 & 05:02 & $04: 59$ & 05:05 \\
\hline $55-59$ & $05: 26$ & $05: 22$ & $05: 21$ & $05: 28$ & $05: 25$ & $05: 13$ & $05: 13$ & $05: 13$ & $05: 13$ & $05: 15$ & $05: 15$ & $05: 15$ & $05: 10$ & $05: 16$ \\
\hline $60-64$ & $05: 25$ & $05: 28$ & $05: 24$ & $05: 29$ & $05: 35$ & $05: 22$ & $05: 26$ & $05: 32$ & $05: 30$ & $05: 30$ & $05: 32$ & $05: 30$ & $05: 26$ & $05: 29$ \\
\hline $65-69$ & $05: 20$ & $05: 25$ & $05: 35$ & $05: 37$ & $05: 30$ & $05: 40$ & $05: 27$ & $05: 36$ & $05: 40$ & $05: 42$ & $05: 37$ & $05: 36$ & $05: 40$ & $05: 44$ \\
\hline $70-74$ & $06: 25$ & $06: 17$ & $05: 58$ & 06:08 & $05: 50$ & $05: 53$ & $05: 53$ & $05: 43$ & $05: 44$ & $05: 49$ & 06:03 & $05: 58$ & $05: 52$ & 06:09 \\
\hline $75-79$ & & $06: 32$ & 06:39 & $06: 40$ & $06: 25$ & $06: 23$ & $06: 39$ & $06: 17$ & $05: 23$ & $06: 26$ & $06: 19$ & $06: 36$ & $06: 14$ & $06: 21$ \\
\hline \multicolumn{15}{|l|}{ Overall } \\
\hline Pro & 09:39 & 09:29 & 09:34 & $09: 22$ & $09: 21$ & 09:20 & $09: 22$ & 09:19 & 09:06 & 09:07 & 09:11 & 09:08 & 09:09 & $09: 13$ \\
\hline $18-24$ & $12: 20$ & $12: 31$ & $12: 25$ & $12: 17$ & $12: 23$ & $12: 25$ & $12: 29$ & $12: 25$ & $12: 21$ & $12: 27$ & $12: 37$ & $12: 25$ & $12: 34$ & $12: 38$ \\
\hline $25-29$ & $12: 21$ & $12: 12$ & $12: 06$ & $12: 02$ & $12: 12$ & $11: 51$ & $12: 02$ & $11: 59$ & $12: 07$ & $12: 13$ & $12: 23$ & $12: 14$ & $12: 17$ & $12: 27$ \\
\hline $30-34$ & $12: 19$ & $12: 14$ & $12: 16$ & $12: 04$ & $12: 13$ & $12: 03$ & $12: 07$ & $11: 58$ & $12: 02$ & $12: 04$ & $12: 12$ & $12: 08$ & $12: 13$ & $12: 22$ \\
\hline $35-39$ & $12: 22$ & $12: 25$ & $12: 16$ & $12: 13$ & $12: 24$ & $12: 15$ & $12: 15$ & $12: 08$ & $12: 14$ & $12: 12$ & $12: 16$ & $12: 16$ & $12: 16$ & $12: 23$ \\
\hline $40-44$ & $12: 36$ & $12: 35$ & $12: 35$ & $12: 22$ & $12: 35$ & $12: 25$ & $12: 26$ & $12: 20$ & $12: 24$ & $12: 23$ & $12: 30$ & $12: 26$ & $12: 30$ & $12: 36$ \\
\hline $45-49$ & $13: 00$ & $12: 55$ & $12: 51$ & $12: 47$ & $12: 52$ & $12: 45$ & $12: 42$ & $12: 33$ & $12: 34$ & $12: 36$ & $12: 42$ & $12: 39$ & $12: 41$ & $12: 50$ \\
\hline $50-54$ & $13: 24$ & $13: 21$ & $13: 16$ & $13: 10$ & $13: 20$ & $13: 05$ & $13: 00$ & $12: 57$ & $13: 00$ & $12: 58$ & $13: 04$ & $13: 03$ & $13: 00$ & $13: 09$ \\
\hline $55-59$ & $13: 55$ & $13: 38$ & $13: 45$ & $13: 45$ & $13: 52$ & $13: 30$ & $13: 29$ & $13: 25$ & $13: 23$ & $13: 29$ & $13: 29$ & $13: 32$ & $13: 24$ & $13: 31$ \\
\hline $60-64$ & $13: 53$ & $13: 59$ & $14: 07$ & $13: 56$ & $14: 15$ & $13: 54$ & $13: 54$ & $14: 04$ & $14: 02$ & $14: 00$ & $14: 06$ & $13: 59$ & $13: 55$ & $13: 57$ \\
\hline $65-69$ & $13: 46$ & $14: 14$ & $14: 46$ & $14: 23$ & $14: 21$ & $14: 42$ & $14: 12$ & $14: 26$ & $14: 24$ & $14: 29$ & $14: 27$ & $14: 23$ & $14: 35$ & $14: 28$ \\
\hline $70-74$ & $15: 29$ & $15: 27$ & $15: 34$ & $15: 29$ & $14: 52$ & $15: 11$ & $15: 11$ & $14: 53$ & $14: 42$ & $14: 59$ & $15: 21$ & $15: 03$ & $15: 02$ & $15: 21$ \\
\hline $75-79$ & & $16: 08$ & $16: 06$ & $16: 15$ & $15: 56$ & $16: 08$ & $16: 18$ & $15: 55$ & $14: 40$ & $15: 57$ & $15: 51$ & $16: 06$ & $15: 34$ & $15: 41$ \\
\hline
\end{tabular}


Table 5 Results of the mixed-effects regression analysis for swimming by age group, $\mathrm{SE}=$ standard error

\begin{tabular}{|c|c|c|c|c|c|c|}
\hline Age group & & Estimate & SE & df & $\mathbf{t}$ & p \\
\hline \multirow[t]{3}{*}{ Pro } & constant term & 277.97 & 380.01 & 7779.19 & 7.31 & $<0.001$ \\
\hline & {$[\mathrm{sex}=$ female $]$} & 5.21 & 0.29 & 2216.21 & 18.00 & $<0.001$ \\
\hline & year & -0.11 & 0.02 & 7779.25 & -5.85 & $<0.001$ \\
\hline \multirow[t]{3}{*}{$18-24$} & constant term & -427.78 & 74.81 & 10178.61 & -5.72 & $<0.001$ \\
\hline & {$[\mathrm{sex}=$ female $]$} & 2.58 & 0.36 & 82330.06 & 7.12 & $<0.001$ \\
\hline & year & 0.25 & 0.04 & 10178.64 & 6.70 & $<0.001$ \\
\hline \multirow[t]{3}{*}{$25-29$} & constant term & -7600.08 & 38.97 & 36135.00 & -19.51 & $<0.001$ \\
\hline & {$[\mathrm{sex}=$ female $]$} & 3.48 & 0.16 & 36135.00 & 21.88 & $<0.001$ \\
\hline & year & 0.41 & 0.02 & 36135.00 & 21.39 & $<0.001$ \\
\hline \multirow[t]{3}{*}{$30-34$} & constant term & -553.21 & 29.13 & 64744.73 & -18.99 & $<0.001$ \\
\hline & {$[\mathrm{sex}=$ female $]$} & 4.72 & 0.14 & 48044.14 & 33.85 & $<0.001$ \\
\hline & year & 0.31 & 0.01 & 64745.00 & 21.56 & $<0.001$ \\
\hline \multirow[t]{3}{*}{$35-39$} & constant term & -344.33 & 27.31 & 78477.27 & -12.61 & $<0.001$ \\
\hline & [sex=female] & 60.02 & 0.14 & 55144.75 & 43.90 & $<0.001$ \\
\hline & year & 0.21 & 0.01 & 78477.73 & 15.39 & $<0.001$ \\
\hline \multirow[t]{3}{*}{$40-44$} & constant term & -285.13 & 27.72 & 84984.78 & -10.29 & $<0.001$ \\
\hline & {$[\mathrm{sex}=$ female $]$} & 5.90 & 0.14 & 56975.85 & 41.89 & $<0.001$ \\
\hline & year & 0.18 & 0.01 & 849850.08 & 130.08 & $<0.001$ \\
\hline \multirow[t]{3}{*}{$45-49$} & constant term & -950.05 & 350.01 & 59926.48 & -2.72 & 0.01 \\
\hline & {$[$ sex $=$ female $]$} & 6.00 & 0.17 & 39109.74 & 34.71 & $<0.001$ \\
\hline & year & 0.09 & 0.02 & 59926.94 & 4.98 & $<0.001$ \\
\hline \multirow[t]{3}{*}{$50-54$} & constant term & 111.67 & 48.16 & 35658.49 & 2.32 & 0.02 \\
\hline & {$[\mathrm{sex}=$ female $]$} & 5.28 & 0.23 & 23584.18 & 22.95 & $<0.001$ \\
\hline & year & -0.02 & 0.02 & 35658.94 & -0.63 & 0.53 \\
\hline \multirow[t]{3}{*}{$55-59$} & constant term & 220.29 & 74.57 & 14167.97 & 2.95 & $<0.001$ \\
\hline & [sex=female] & 50.04 & 0.38 & 9214.42 & 13.18 & $<0.001$ \\
\hline & year & -0.07 & 0.04 & 14168.31 & -1.83 & 0.07 \\
\hline \multirow[t]{3}{*}{$60-64$} & constant term & 696.34 & 121.97 & 5550.71 & 5.71 & $<0.001$ \\
\hline & {$[\mathrm{sex}=$ female $]$} & 5.20 & 0.67 & 3573.80 & 7.75 & $<0.001$ \\
\hline & year & -0.30 & 0.06 & 5550.83 & -4.99 & $<0.001$ \\
\hline \multirow[t]{3}{*}{$65-69$} & constant term & 900.77 & 2240.08 & 1658.22 & 40.02 & $<0.001$ \\
\hline & [sex $=$ female $]$ & 5.95 & 1.37 & 1033.99 & 4.33 & $<0.001$ \\
\hline & year & -0.40 & 0.11 & 1658.29 & -3.61 & $<0.001$ \\
\hline \multirow[t]{3}{*}{$70-74$} & constant term & 663.94 & 393.71 & 448.79 & 1.69 & 0.09 \\
\hline & & 10.19 & 3.17 & 321.61 & 3.21 & $<0.001$ \\
\hline & year & -0.28 & 0.20 & 448.80 & -1.44 & 0.15 \\
\hline \multirow[t]{3}{*}{$75-79$} & constant term & 1126.12 & 881.95 & 86.12 & 1.28 & 0.21 \\
\hline & {$[\mathrm{sex}=$ female $]$} & 8.32 & 7.13 & 440.03 & 1.17 & 0.25 \\
\hline & year & -0.51 & 0.44 & 86.16 & -1.16 & 0.25 \\
\hline
\end{tabular}


Table 6 Results of the mixed-effects regression analysis for cycling by age group, $\mathrm{SE}=$ standard error

\begin{tabular}{|c|c|c|c|c|c|c|}
\hline Age group & & Estimate & SE & df & $\mathbf{t}$ & p \\
\hline \multirow[t]{3}{*}{ Pro } & constant term & 2139.29 & 145.46 & 7465.40 & 14.71 & $<0.001$ \\
\hline & {$[\mathrm{sex}=$ female $]$} & 28.13 & 0.88 & 1984.76 & 31.88 & $<0.001$ \\
\hline & year & -0.91 & 0.07 & 7464.94 & -12.64 & $<0.001$ \\
\hline \multirow[t]{3}{*}{$18-24$} & constant term & -680.47 & 275.83 & 9875.53 & -2.47 & 0.01 \\
\hline & {$[\mathrm{sex}=$ female $]$} & 30.40 & 1.31 & 8254.80 & 23.12 & $<0.001$ \\
\hline & year & 0.53 & 0.14 & 9875.58 & 3.84 & $<0.001$ \\
\hline \multirow[t]{3}{*}{$25-29$} & constant term & -666.88 & 147.78 & 34328.77 & -4.51 & $<0.001$ \\
\hline & {$[\mathrm{sex}=$ female $]$} & 33.76 & 0.65 & 27653.35 & 51.80 & $<0.001$ \\
\hline & year & 0.52 & 0.07 & 343290.03 & 70.03 & $<0.001$ \\
\hline \multirow[t]{3}{*}{$30-34$} & constant term & -394.41 & 104.87 & 63241.86 & -3.76 & $<0.001$ \\
\hline & {$[\mathrm{sex}=$ female $]$} & 36.23 & 0.49 & 48284.55 & 73.54 & $<0.001$ \\
\hline & year & 0.38 & 0.05 & 63242.28 & 7.29 & $<0.001$ \\
\hline \multirow[t]{3}{*}{$35-39$} & constant term & 180.60 & 97.44 & 77324.37 & 1.85 & 0.06 \\
\hline & {$[\mathrm{sex}=$ female $]$} & 36.98 & 0.48 & 55384.28 & 76.61 & $<0.001$ \\
\hline & year & 0.09 & 0.05 & 77324.97 & 1.96 & 0.05 \\
\hline \multirow[t]{3}{*}{$40-44$} & constant term & 64.94 & 97.28 & 83204.65 & 0.67 & 0.50 \\
\hline & {$[\mathrm{sex}=$ female $]$} & 35.63 & 0.48 & 57107.63 & 73.72 & $<0.001$ \\
\hline & year & 0.15 & 0.05 & 83205.13 & 3.19 & $<0.001$ \\
\hline \multirow[t]{3}{*}{$45-49$} & constant term & 350.54 & 119.27 & 587510.05 & 2.94 & $<0.001$ \\
\hline & {$[\mathrm{sex}=$ female $]$} & 34.37 & 0.58 & 39374.55 & 59.52 & $<0.001$ \\
\hline & year & 0.01 & 0.06 & 58751.71 & 0.25 & 0.80 \\
\hline \multirow[t]{3}{*}{$50-54$} & constant term & 584.32 & 158.12 & 34761.82 & 3.70 & $<0.001$ \\
\hline & {$[\mathrm{sex}=$ female $]$} & 33.73 & 0.74 & 23718.97 & 45.65 & $<0.001$ \\
\hline & year & -0.10 & 0.08 & 34762.54 & -1.24 & 0.22 \\
\hline \multirow[t]{3}{*}{$55-59$} & constant term & 681.90 & 240.66 & 137300.07 & 2.83 & 0.01 \\
\hline & {$[\mathrm{sex}=$ female $]$} & 31.41 & 1.21 & 9284.81 & 25.97 & $<0.001$ \\
\hline & year & -0.14 & 0.12 & 13730.52 & -1.18 & 0.24 \\
\hline \multirow[t]{3}{*}{$60-64$} & constant term & 417.51 & 362.44 & 5563.77 & 1.15 & 0.25 \\
\hline & [sex=female $]$ & 30.81 & 2.00 & 3621.15 & 15.44 & $<0.001$ \\
\hline & year & 0.00 & & 5563.89 & -0.02 & 0.98 \\
\hline \multirow[t]{3}{*}{$65-69$} & constant term & 342.85 & 619.92 & 1608.17 & 0.55 & 0.58 \\
\hline & {$[\mathrm{sex}=$ female $]$} & 270.09 & 3.74 & 1032.62 & 7.24 & $<0.001$ \\
\hline & year & 0.04 & 0.31 & 1608.25 & 0.13 & 0.90 \\
\hline \multirow[t]{3}{*}{$70-74$} & constant term & 167.99 & 996.37 & 454.19 & 0.17 & 0.87 \\
\hline & {$[\mathrm{sex}=$ female $]$} & 22.21 & 80.07 & 3170.06 & 2.75 & 0.01 \\
\hline & year & 0.13 & 0.50 & 454.19 & 0.27 & 0.79 \\
\hline \multirow[t]{3}{*}{$75-79$} & constant term & 2026.97 & 1651.49 & 73.35 & 1.23 & 0.22 \\
\hline & [sex=female] & 23.51 & 13.19 & 34.26 & 1.78 & 0.08 \\
\hline & year & -0.78 & 0.82 & 73.40 & -0.96 & 0.34 \\
\hline
\end{tabular}


Table 7 Results of the mixed-effects regression analysis for running by age group, $\mathrm{SE}=$ standard error

\begin{tabular}{|c|c|c|c|c|c|c|}
\hline Age group & & Estimate & SE & df & $\mathbf{t}$ & p \\
\hline \multirow[t]{3}{*}{ Pro } & constant term & 1502.39 & 2270.07 & 7056.57 & 6.62 & $<0.001$ \\
\hline & {$[\mathrm{sex}=$ female $]$} & 14.47 & 1.31 & 1802.23 & 110.08 & $<0.001$ \\
\hline & year & -0.64 & 0.11 & 7055.80 & -5.71 & $<0.001$ \\
\hline \multirow[t]{3}{*}{$18-24$} & constant term & 683.69 & 322.27 & 9625.57 & 2.12 & 0.03 \\
\hline & [sex=female $]$ & 14.65 & 1.51 & 8277.27 & 9.67 & $<0.001$ \\
\hline & year & -0.20 & 0.16 & 9625.65 & -1.22 & 0.22 \\
\hline \multirow[t]{3}{*}{$25-29$} & constant term & 586.37 & 170.45 & 33535.99 & 3.44 & $<0.001$ \\
\hline & {$[\mathrm{sex}=$ female $]$} & 17.33 & 0.74 & 27903.86 & 23.40 & $<0.001$ \\
\hline & year & -0.15 & 0.08 & 33536.36 & -1.78 & 0.08 \\
\hline \multirow[t]{3}{*}{$30-34$} & constant term & 1154.75 & 122.37 & 61888.35 & 9.44 & $<0.001$ \\
\hline & {$[\mathrm{sex}=$ female $]$} & 20.13 & 0.57 & 487110.02 & 35.55 & $<0.001$ \\
\hline & year & -0.43 & 0.06 & 61888.89 & -7.14 & $<0.001$ \\
\hline \multirow[t]{3}{*}{$35-39$} & constant term & 1103.47 & 114.24 & 75860.81 & 9.66 & $<0.001$ \\
\hline & {$[\mathrm{sex}=$ female $]$} & 20.72 & 0.56 & 55906.76 & 37.15 & $<0.001$ \\
\hline & year & -0.41 & 0.06 & 75861.58 & -7.18 & $<0.001$ \\
\hline \multirow[t]{3}{*}{$40-44$} & constant term & 235.72 & 113.10 & 82149.55 & 20.08 & 0.04 \\
\hline & {$[\mathrm{sex}=$ female $]$} & 20.63 & 0.56 & 57765.16 & 37.13 & $<0.001$ \\
\hline & year & 0.03 & 0.06 & 82150.13 & 0.47 & 0.64 \\
\hline \multirow[t]{3}{*}{$45-49$} & constant term & -298.69 & 138.87 & 58165.20 & -2.15 & 0.03 \\
\hline & {$[\mathrm{sex}=$ female $]$} & 21.38 & 0.67 & 39781.35 & 320.08 & $<0.001$ \\
\hline & year & 0.30 & 0.07 & 58165.96 & 4.28 & $<0.001$ \\
\hline \multirow[t]{3}{*}{$50-54$} & constant term & -328.53 & 183.67 & 34616.38 & -1.79 & 0.07 \\
\hline & {$[\mathrm{sex}=$ female $]$} & 21.14 & 0.85 & 23984.32 & 24.73 & $<0.001$ \\
\hline & year & 0.32 & 0.09 & 34617.14 & 3.45 & $<0.001$ \\
\hline \multirow[t]{3}{*}{$55-59$} & constant term & -492.60 & 278.78 & 14034.13 & -1.77 & 0.08 \\
\hline & {$[\mathrm{sex}=$ female $]$} & 17.00 & 1.42 & 9401.64 & 11.99 & $<0.001$ \\
\hline & year & 0.40 & 0.14 & 14034.50 & 2.91 & $<0.001$ \\
\hline \multirow[t]{3}{*}{$60-64$} & constant term & -2123.87 & 432.70 & 5658.24 & -4.91 & $<0.001$ \\
\hline & {$[\mathrm{sex}=$ female $]$} & 16.18 & 2.40 & 3663.69 & 6.73 & $<0.001$ \\
\hline & year & 1.22 & 0.22 & 5658.34 & 5.67 & $<0.001$ \\
\hline \multirow[t]{3}{*}{$65-69$} & constant term & -3399.83 & 721.72 & 1776.27 & -4.71 & $<0.001$ \\
\hline & [sex=female] & 24.48 & & 1088.64 & 5.37 & $<0.001$ \\
\hline & year & 1.86 & 0.36 & 1776.32 & 5.19 & $<0.001$ \\
\hline \multirow[t]{3}{*}{$70-74$} & constant term & -2524.23 & 1158.59 & 466.43 & -2.18 & 0.03 \\
\hline & {$[\mathrm{sex}=$ female $]$} & 11.69 & 9.46 & 3180.09 & 1.24 & 0.22 \\
\hline & year & 1.43 & 0.58 & 466.44 & 2.49 & 0.01 \\
\hline \multirow[t]{3}{*}{$75-79$} & constant term & -3824.78 & 2466.20 & 107.21 & -1.55 & 0.12 \\
\hline & {$[\mathrm{sex}=$ female $]$} & 15.48 & 22.93 & 48.82 & 0.68 & 0.50 \\
\hline & year & 20.09 & 1.23 & 107.23 & 1.71 & 0.09 \\
\hline
\end{tabular}


Table 8 Results of the mixed-effects regression analysis for overall race time by age group, $\mathrm{SE}=$ standard error

\begin{tabular}{|c|c|c|c|c|c|c|}
\hline Pro & $\begin{array}{c}\text { constant term } \\
{\left[\begin{array}{c}\text { sex=female }] \\
\text { year }\end{array}\right.}\end{array}$ & $\begin{array}{c}3577.79 \\
48.32 \\
-1.50\end{array}$ & $\begin{array}{l}325.71 \\
2.14 \\
0.16\end{array}$ & $\begin{array}{l}77610.06 \\
2022.40 \\
7760.90\end{array}$ & $\begin{array}{l}10.99 \\
22.63 \\
-9.24\end{array}$ & $\begin{array}{l}<0.001 \\
<0.001 \\
<0.001\end{array}$ \\
\hline \multirow[t]{3}{*}{$18-24$} & constant term & -3330.06 & 598.25 & 10015.13 & -0.56 & 0.58 \\
\hline & {$[\mathrm{sex}=$ female $]$} & 47.76 & 2.87 & 8325.27 & 16.64 & $<0.001$ \\
\hline & year & 0.54 & 0.30 & 10015.17 & 1.82 & 0.07 \\
\hline \multirow[t]{3}{*}{$25-29$} & constant term & -714.50 & 320.79 & 34842.37 & -2.23 & 0.03 \\
\hline & [sex=female] & 55.14 & 1.43 & 278850.07 & 38.64 & $<0.001$ \\
\hline & year & 0.72 & 0.16 & 34842.56 & 4.54 & $<0.001$ \\
\hline \multirow[t]{3}{*}{$30-34$} & constant term & 31.21 & 228.94 & 64570.54 & 0.14 & 0.89 \\
\hline & [sex=female $]$ & 62.22 & 10.09 & 48768.60 & 570.01 & $<0.001$ \\
\hline & year & 0.35 & 0.11 & 64570.82 & 30.10 & $<0.001$ \\
\hline \multirow[t]{3}{*}{$35-39$} & constant term & 677.87 & 2120.01 & 79004.66 & 3.20 & $<0.001$ \\
\hline & {$[\mathrm{sex}=$ female $]$} & 65.17 & 10.07 & 55991.28 & 60.89 & $<0.001$ \\
\hline & year & 0.03 & 0.11 & 790050.05 & 0.32 & 0.75 \\
\hline \multirow[t]{3}{*}{$40-44$} & constant term & -358.89 & 208.43 & 85269.62 & -1.72 & 0.09 \\
\hline & {$[$ sex $=$ female $]$} & 63.52 & 10.06 & 57895.49 & 59.82 & $<0.001$ \\
\hline & year & 0.55 & 0.10 & 85269.89 & 5.35 & $<0.001$ \\
\hline \multirow[t]{3}{*}{$45-49$} & constant term & -798.14 & 2530.07 & 60477.39 & -3.15 & $<0.001$ \\
\hline & [sex=female] & 62.93 & 1.26 & 39891.68 & 49.91 & $<0.001$ \\
\hline & year & 0.78 & 0.13 & 60477.73 & 6.20 & $<0.001$ \\
\hline \multirow[t]{3}{*}{$50-54$} & constant term & -474.49 & 330.55 & 360370.05 & -1.44 & 0.15 \\
\hline & {$[\mathrm{sex}=$ female $]$} & 60.90 & 1.60 & 24092.42 & 38.11 & $<0.001$ \\
\hline & year & 0.63 & 0.16 & 36037.37 & 3.83 & $<0.001$ \\
\hline \multirow[t]{3}{*}{$55-59$} & constant term & -625.38 & 498.19 & 14526.63 & -1.26 & 0.21 \\
\hline & [sex=female $]$ & 53.68 & 2.60 & 9397.97 & 20.67 & $<0.001$ \\
\hline & year & 0.72 & 0.25 & 14526.87 & 2.90 & $<0.001$ \\
\hline \multirow[t]{3}{*}{$60-64$} & constant term & -2230.46 & 7500.06 & 5836.31 & -2.97 & $<0.001$ \\
\hline & [sex=female] & 51.87 & 4.26 & 3679.86 & 12.18 & $<0.001$ \\
\hline & year & 1.53 & 0.37 & 5836.38 & 4.10 & $<0.001$ \\
\hline \multirow[t]{3}{*}{$65-69$} & constant term & -2849.13 & 1239.63 & 1729.65 & -2.30 & 0.02 \\
\hline & [sex=female $]$ & 57.40 & 7.72 & 1076.19 & 7.43 & $<0.001$ \\
\hline & year & 1.85 & 0.62 & 1729.71 & 30.01 & $<0.001$ \\
\hline \multirow[t]{3}{*}{$70-74$} & constant term & -2585.82 & 1889.14 & 463.18 & -1.37 & 0.17 \\
\hline & {$[\mathrm{sex}=$ female $]$} & 42.13 & 15.44 & 313.56 & 2.73 & 0.01 \\
\hline & year & 1.74 & 0.94 & 463.19 & 1.85 & 0.07 \\
\hline \multirow[t]{3}{*}{$75-79$} & constant term & 350.21 & 29900.05 & 84.46 & 0.12 & 0.91 \\
\hline & [sex=female $]$ & 54.25 & 24.99 & 40.78 & 2.17 & 0.04 \\
\hline & & 0.30 & 1.49 & 84.50 & 0.20 & 0.84 \\
\hline
\end{tabular}


Table 9 Sex difference (\%) in split and overall race times by age group

\begin{tabular}{|c|c|c|c|c|c|c|c|c|c|c|c|c|c|c|}
\hline & 2002 & 2003 & 2004 & 2005 & 2006 & 2007 & 2008 & 2009 & 2010 & 2011 & 2012 & 2013 & 2014 & 2015 \\
\hline \multicolumn{15}{|l|}{ Swimming } \\
\hline Pro & 10.51 & 7.55 & 8.46 & 11.04 & 10.80 & 6.59 & 10.58 & 10.46 & 10.80 & 9.50 & 12.56 & 9.96 & 10.28 & 8.12 \\
\hline $18-24$ & -2.49 & 2.76 & 3.82 & 7.71 & 6.27 & 4.15 & 1.23 & 3.21 & 2.03 & 1.24 & 4.22 & 5.74 & 4.19 & 0.99 \\
\hline $25-29$ & 6.72 & 5.56 & 7.26 & 6.66 & 8.02 & 7.35 & 5.34 & 5.55 & 4.99 & 3.77 & 3.73 & 3.74 & 3.61 & 2.95 \\
\hline $30-34$ & 4.98 & 6.71 & 6.40 & 7.63 & 8.73 & 7.44 & 5.49 & 7.08 & 7.34 & 7.33 & 7.13 & 6.95 & 5.45 & 3.71 \\
\hline $35-39$ & 6.72 & 9.35 & 8.46 & 8.81 & 7.53 & 9.23 & 8.10 & 8.76 & 7.53 & 8.89 & 8.29 & 7.65 & 7.49 & 5.54 \\
\hline $40-44$ & 3.36 & 8.49 & 6.45 & 7.30 & 7.58 & 8.81 & 7.38 & 8.59 & 7.68 & 9.00 & 8.97 & 7.50 & 7.39 & 5.33 \\
\hline $45-49$ & 9.15 & 7.85 & 8.01 & 7.66 & 9.02 & 8.72 & 6.50 & 8.00 & 7.82 & 8.97 & 7.12 & 8.18 & 8.21 & 6.00 \\
\hline $50-54$ & 12.70 & 6.15 & 7.75 & 8.77 & 7.06 & 7.05 & 9.30 & 8.83 & 6.55 & 6.93 & 6.13 & 7.27 & 6.31 & 4.47 \\
\hline $55-59$ & 13.36 & 7.30 & 11.40 & 9.63 & 12.26 & 9.76 & 7.02 & 7.20 & 6.98 & 5.34 & 7.31 & 6.08 & 6.21 & 3.24 \\
\hline $60-64$ & & 8.25 & 4.27 & 9.53 & 9.71 & 9.03 & 4.30 & 8.42 & 3.62 & 9.85 & 4.91 & 9.73 & 9.16 & 4.47 \\
\hline $65-69$ & & 17.55 & 18.38 & 12.68 & 4.22 & 5.66 & 1.11 & 7.53 & 12.26 & 8.87 & 7.05 & 4.47 & 11.97 & 0.67 \\
\hline $70-74$ & & & 15.95 & 15.47 & 14.70 & 18.76 & 15.92 & 7.90 & & 20.69 & 4.30 & 18.68 & 7.57 & 6.09 \\
\hline $75-79$ & & & & 14.50 & 14.20 & & 3.46 & 12.49 & 12.18 & 22.77 & 16.01 & 35.13 & & \\
\hline \multicolumn{15}{|l|}{ Cycling } \\
\hline Pro & 4.32 & 9.82 & 9.87 & 11.55 & 10.75 & 10.01 & 10.08 & 9.27 & 10.78 & 10.03 & 10.19 & 9.20 & 8.38 & 9.84 \\
\hline $18-24$ & 5.87 & 7.20 & 8.56 & 10.40 & 10.17 & 8.29 & 7.02 & 9.13 & 7.54 & 6.20 & 6.75 & 7.52 & 7.68 & 7.38 \\
\hline $25-29$ & 9.88 & 10.40 & 10.28 & 10.70 & 9.30 & 11.32 & 11.84 & 10.09 & 9.66 & 7.68 & 7.57 & 8.45 & 7.13 & 7.75 \\
\hline $30-34$ & 8.80 & 11.01 & 10.00 & 10.91 & 10.64 & 11.42 & 10.62 & 10.85 & 10.29 & 9.16 & 8.56 & 9.60 & 8.75 & 8.73 \\
\hline $35-39$ & 8.50 & 9.95 & 10.44 & 11.27 & 9.63 & 10.67 & 10.87 & 10.87 & 10.04 & 9.55 & 9.61 & 9.05 & 9.55 & 8.76 \\
\hline $40-44$ & 6.02 & 8.88 & 8.73 & 9.75 & 8.98 & 10.20 & 10.49 & 10.49 & 9.28 & 8.85 & 9.05 & 9.31 & 9.39 & 8.89 \\
\hline $45-49$ & 11.32 & 10.09 & 8.96 & 9.29 & 9.34 & 9.00 & 9.74 & 10.02 & 9.98 & 8.90 & 8.13 & 8.73 & 9.32 & 7.97 \\
\hline $50-54$ & 5.12 & 6.68 & 10.27 & 9.10 & 8.16 & 8.44 & 10.77 & 10.51 & 8.41 & 8.60 & 7.83 & 8.52 & 8.82 & 8.12 \\
\hline $55-59$ & 7.23 & 4.82 & 8.72 & 7.41 & 8.94 & 9.38 & 8.88 & 8.06 & 8.72 & 7.67 & 8.16 & 6.13 & 8.21 & 7.73 \\
\hline $60-64$ & & 10.50 & 8.23 & 7.66 & 4.01 & 8.76 & 9.07 & 8.67 & 4.92 & 7.89 & 8.14 & 7.83 & 9.21 & 6.86 \\
\hline $65-69$ & & 9.37 & 9.16 & 9.42 & 9.46 & 11.49 & 10.36 & 8.99 & 7.18 & 4.02 & 4.60 & 3.66 & 5.21 & 7.52 \\
\hline $70-74$ & & & 7.64 & 4.77 & 14.09 & 9.44 & 2.33 & 4.99 & & 12.14 & 3.24 & 10.56 & 4.15 & 2.45 \\
\hline 75-79 & & & & 1.21 & 5.74 & & 9.26 & 2.87 & 2.74 & 2.91 & 7.92 & 2.14 & & \\
\hline \multicolumn{15}{|l|}{ Running } \\
\hline Pro & 11.80 & 10.88 & 10.15 & 11.12 & 11.12 & 8.92 & 6.83 & 5.81 & 8.80 & 6.06 & 4.54 & 6.26 & 5.36 & 4.50 \\
\hline $18-24$ & 4.73 & 5.79 & 6.18 & 6.71 & 6.32 & 2.20 & 1.09 & 3.61 & 5.22 & 2.73 & 4.47 & 5.90 & 4.21 & 4.50 \\
\hline $25-29$ & 4.66 & 5.16 & 6.48 & 5.22 & 5.95 & 8.75 & 7.93 & 7.22 & 7.08 & 4.98 & 5.88 & 6.30 & 3.95 & 5.13 \\
\hline $30-34$ & 6.81 & 5.16 & 5.54 & 7.25 & 8.13 & 7.21 & 6.48 & 7.89 & 7.89 & 8.36 & 6.50 & 7.45 & 6.46 & 6.66 \\
\hline $35-39$ & 5.99 & 5.83 & 6.72 & 6.76 & 7.16 & 6.47 & 7.52 & 7.51 & 6.24 & 8.40 & 7.76 & 6.39 & 6.98 & 6.23 \\
\hline $40-44$ & 3.63 & 6.10 & 5.01 & 5.64 & 6.27 & 5.97 & 7.30 & 7.77 & 7.34 & 7.69 & 6.94 & 7.40 & 6.29 & 6.05 \\
\hline $45-49$ & 5.05 & 5.36 & 4.22 & 7.13 & 7.87 & 5.20 & 6.69 & 7.47 & 7.83 & 8.03 & 7.50 & 7.50 & 8.06 & 6.12 \\
\hline $50-54$ & 0.35 & 4.92 & 8.82 & 5.13 & 7.15 & 6.33 & 9.21 & 8.13 & 6.31 & 7.88 & 6.59 & 6.08 & 5.69 & 5.73 \\
\hline $55-59$ & 3.45 & 1.98 & 4.51 & 2.52 & 5.77 & 6.41 & 6.10 & 6.67 & 4.08 & 4.87 & 5.33 & 4.02 & 6.33 & 4.60 \\
\hline $60-64$ & & 5.79 & 2.36 & 8.23 & 8.05 & 5.85 & 4.11 & 4.41 & 0.62 & 6.54 & 2.79 & 6.67 & 4.82 & 4.99 \\
\hline $65-69$ & & 16.64 & 11.34 & 8.94 & 9.37 & 4.41 & 14.29 & 10.85 & 7.00 & 2.66 & 4.45 & 7.08 & 5.96 & 7.88 \\
\hline $70-74$ & & & 7.43 & 14.81 & 7.50 & 9.66 & 11.90 & 25.89 & & 10.99 & 10.06 & 1.81 & -1.04 & 1.14 \\
\hline 75-79 & & & & 2.55 & 0.36 & & 1.23 & 15.06 & 23.46 & 5.93 & 1.27 & 1.82 & & \\
\hline \multicolumn{15}{|l|}{ Overall } \\
\hline Pro & 7.36 & 10.06 & 9.76 & 11.38 & 10.86 & 9.27 & 8.90 & 8.10 & 10.08 & 8.43 & 8.40 & 8.22 & 7.40 & 7.68 \\
\hline $18-24$ & 4.85 & 6.06 & 7.08 & 8.78 & 8.35 & 5.34 & 3.91 & 6.23 & 5.95 & 4.23 & 5.42 & 6.56 & 5.72 & 5.41 \\
\hline $25-29$ & 7.32 & 7.92 & 8.45 & 8.16 & 7.97 & 10.02 & 9.70 & 8.52 & 8.14 & 6.18 & 6.41 & 7.04 & 5.39 & 6.15 \\
\hline $30-34$ & 7.74 & 8.30 & 7.84 & 9.16 & 9.58 & 9.55 & 8.47 & 9.35 & 9.07 & 8.67 & 7.58 & 8.47 & 7.40 & 7.37 \\
\hline $35-39$ & 7.34 & 8.24 & 8.70 & 9.34 & 8.47 & 9.00 & 9.30 & 9.36 & 8.29 & 9.04 & 8.77 & 7.86 & 8.27 & 7.44 \\
\hline $40-44$ & 4.68 & 7.78 & 6.98 & 7.89 & 7.71 & 8.47 & 8.89 & 9.23 & 8.38 & 8.41 & 8.24 & 8.38 & 7.90 & 7.42 \\
\hline $45-49$ & 8.52 & 7.77 & 6.82 & 8.24 & 8.72 & 7.42 & 8.17 & 8.77 & 8.91 & 8.57 & 7.78 & 8.20 & 8.65 & 7.06 \\
\hline $50-54$ & 3.57 & 5.67 & 9.32 & 7.47 & 7.46 & 7.45 & 9.92 & 9.34 & 7.29 & 8.13 & 7.10 & 7.40 & 7.23 & 6.77 \\
\hline $55-59$ & 5.60 & 3.53 & 7.09 & 5.65 & 7.70 & 8.27 & 7.42 & 7.31 & 6.54 & 6.28 & 6.90 & 5.04 & 7.11 & 5.99 \\
\hline $60-64$ & & 7.84 & 4.91 & 8.02 & 5.83 & 7.62 & 6.34 & 6.81 & 2.45 & 7.43 & 5.57 & 7.35 & 7.33 & 5.79 \\
\hline $65-69$ & & 13.81 & 10.72 & 9.70 & 8.04 & 8.03 & 10.49 & 9.54 & 6.97 & 3.70 & 4.45 & 5.09 & 6.00 & 6.91 \\
\hline $70-74$ & & & 8.66 & 6.43 & 11.55 & 9.67 & 7.28 & 13.38 & & 12.77 & 5.18 & 7.99 & 2.14 & 1.87 \\
\hline $75-79$ & & & & 0.48 & 6.57 & & 4.56 & 6.12 & 11.35 & 6.08 & 6.24 & 5.20 & & \\
\hline
\end{tabular}



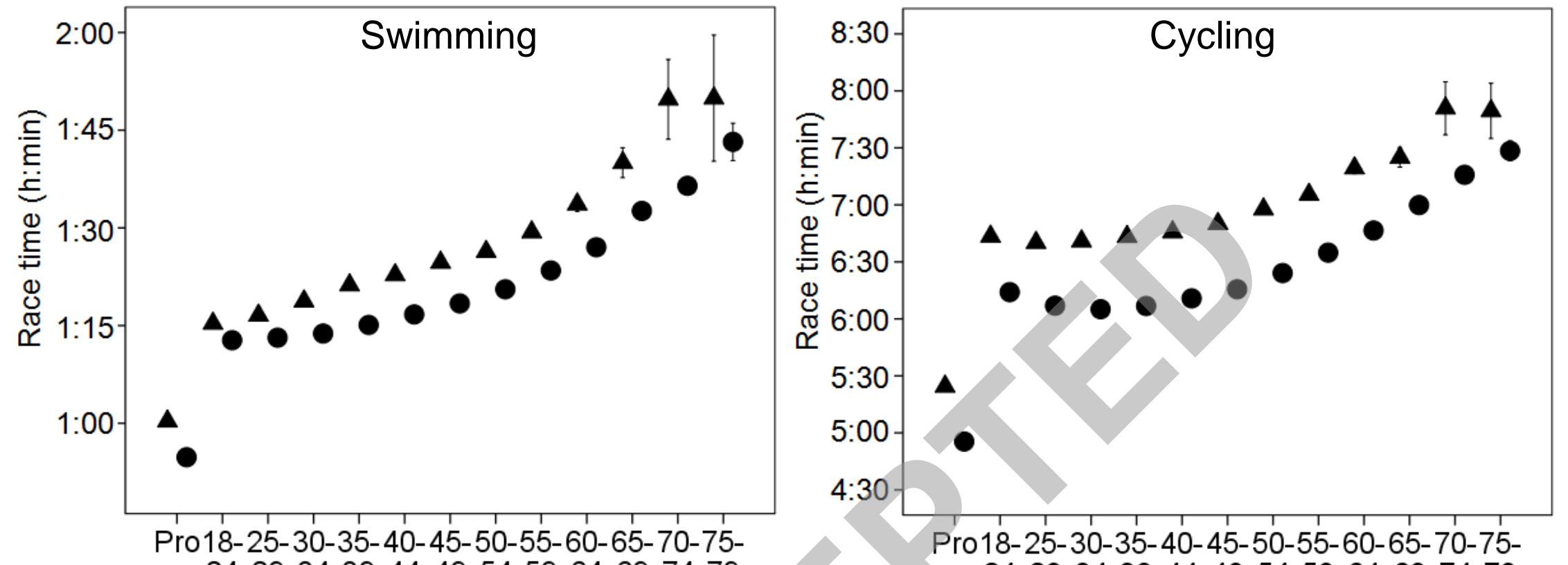

Pro18-25-30-35-40-45-50-55-60-65-70-75242934394449545964697479

242934394449545964697479
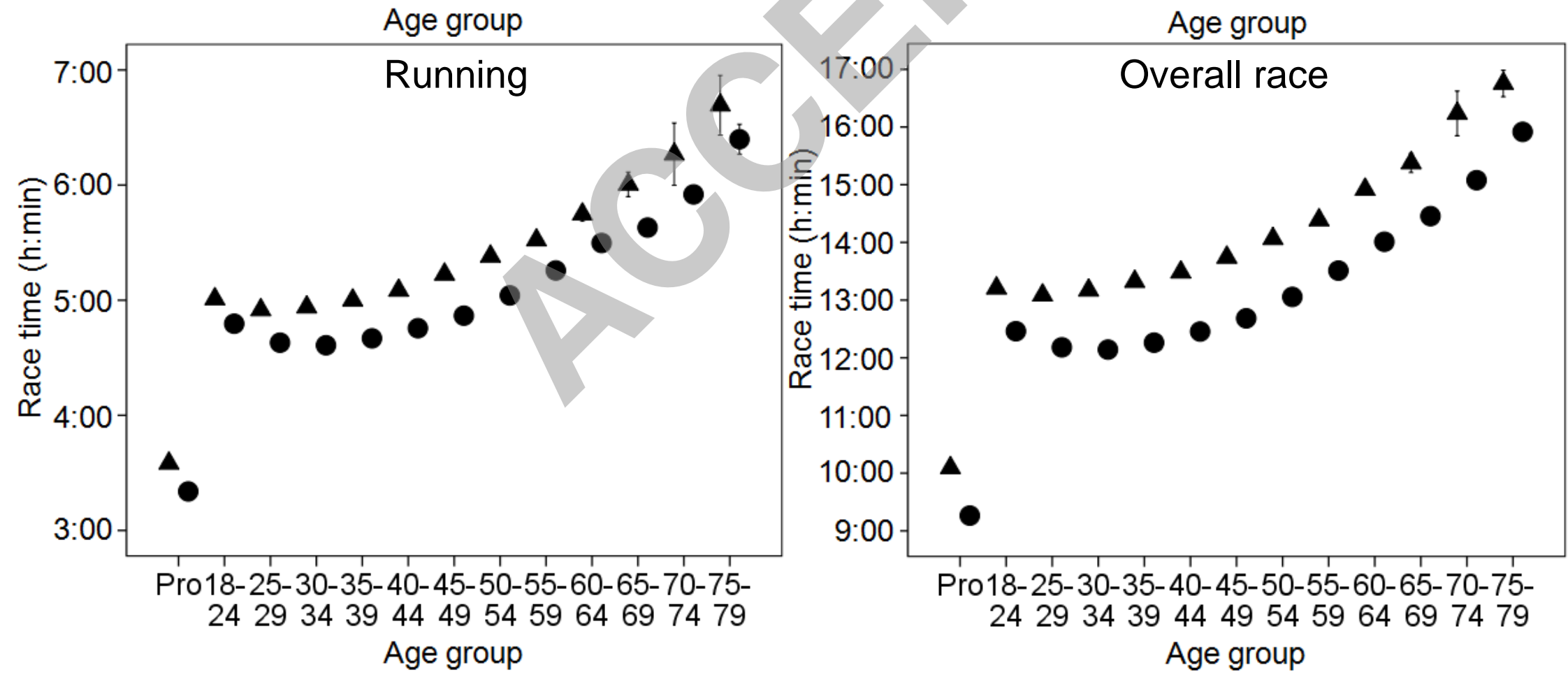

Copyright (c) 2017 National Strength and Conditioning Association 